\title{
A three-site Langmuir adsorption model to elucidate the temperature, pressure, and support dependence of the hydrogen coverage on supported Pt particles
}

\author{
Yaying Ji ${ }^{\mathrm{a}, 1}$, Vincent Koot ${ }^{\mathrm{a}}$, Ad M.J. van der Eerden ${ }^{\mathrm{a}}$, Bert M. Weckhuysen ${ }^{\mathrm{a}}$, \\ Diek C. Koningsberger ${ }^{\mathrm{a}, *}$, David E. Ramaker ${ }^{\mathrm{b}}$ \\ ${ }^{a}$ Group of Inorganic Chemistry and Catalysis, Department of Chemistry, Utrecht University, PO Box 80083, 3508 TB Utrecht, The Netherlands \\ ${ }^{\mathrm{b}}$ Chemistry Department, George Washington University, Washington, DC 20052, USA
}

Received 2 August 2006; revised 24 October 2006; accepted 30 October 2006

Available online 5 December 2006

\begin{abstract}
The three-site adsorption model, previously developed to describe $\mathrm{H}$ adsorption on small $\mathrm{Pt}$ particles, was used to gain insight into dependence of hydrogen coverage on temperature, pressure, and support ionicity. The three sites, in order of decreasing Pt- $\mathrm{H}$ bond strength, involve $\mathrm{H}$ in an atop, a threefold, and an ontop Pt site. The ontop site designates $\mathrm{H}$ bonded in an atop site surrounded by occupied threefold sites (hence referred to as ontop site). The model includes an emptying of the $\mathrm{H}$ atop sites into $\mathrm{H}$ threefold sites with increasing $\mathrm{H}$ pressure to reduce lateral interactions. Hydrogen chemisorption on an acidic Pt/H-USY and a basic Pt/NaY and TPD results on a acidic Pt/H-LTL and basic Pt/K-LTL are modeled using a Langmuir isotherm for each $\mathrm{H}$ site. The $\mathrm{H} / \mathrm{M}$ data can be directly compared with $\mathrm{Pt} L_{2,3}$ XANES results on the same samples. A new analysis method (Delta XANES technique) using the difference in the absorption coefficient, $\Delta \mu=\mu(\mathrm{H} / \mathrm{Pt})-\mu(\mathrm{Pt})$, allows an in situ spectroscopic determination of the type of $\mathrm{H}$ adsorption site and $\mathrm{H}$ coverage. The adsorption enthalpies ( $\Delta H$ 's) for the atop, threefold, and ontop sites are found to be highly dependent on the support ionicity, increasing for ionic (basic) supports consistent with previous results. The calculations using the three-site model confirm that the support-induced changes in the $\mathrm{Pt}-\mathrm{H}$ bond strength produce dramatically different $\mathrm{H}$ coverages and dominant adsorption sites at catalytic reaction temperatures and pressures. Depending on uptake versus desorption of $\mathrm{H}$, a hysteresis is found in the atop to threefold site rearrangement, believed to result from a requirement for collective rearrangement involving an entire domain or island of $\mathrm{H}$ on the surface.
\end{abstract}

(c) 2006 Elsevier Inc. All rights reserved.

Keywords: Three-site hydrogen adsorption model on Pt; Metal-support interaction; Ontop/ $n$-fold/atop hydrogen adsorption sites; Temperature/pressure and support dependence of hydrogen coverage

\section{Introduction}

$\mathrm{H}$ adsorption on supported Pt particles is critical in supported noble metal catalysts, which are widely used in commercially important reactions, including hydrogenation, naphtha reforming, isomerization reactions, and electrocatalysis such as that taking place in a fuel cell [1]. The stimulus for the current work

\footnotetext{
* Corresponding author.

E-mail address: d.c.koningsberger@chem.uu.nl (D.C. Koningsberger).

1 Present address: Center for Applied Energy Research, University of Kentucky, 2540 Research Park Drive, Lexington, KY 40511, USA.
}

is recent advances in X-ray absorption spectroscopy (XAS), which now enable XAS to provide $\mathrm{H}$ binding site information in situ on supported Pt particles both in the gas phase and in an electrochemical cell [2]. These recent advances arise from new data analysis procedures, rather than new experimental techniques.

A new analysis method (Delta XANES technique) has been developed that makes use of the difference in the X-ray absorption coefficient, $\Delta \mu=\mu(\mathrm{H} / \mathrm{Pt})-\mu(\mathrm{Pt})$, with $\mu(\mathrm{H} / \mathrm{Pt})$ the $\mathrm{X}$-ray absorption in the presence of and $\mu(\mathrm{Pt})$ that in the absence of chemisorbed hydrogen. Teliska et al. [3] used this Delta XANES technique to examine Pt particles supported on carbon 
(Pt electrodes), and Oudenhuijzen et al. [4] studied Pt supported on $\mathrm{Al}_{2} \mathrm{O}_{3}$ or dispersed in LTL and $\mathrm{Y}$ zeolite (Pt catalysts). The $\mathrm{Pt} L_{3}$ XANES data of the sample in vacuum or at $0.5 \mathrm{~V}$ in an electrochemical cell (i.e., when the Pt surface is relatively free of $\mathrm{H}$ and other adsorbates) are subtracted from the data obtained after chemisorption of hydrogen: $\Delta \mu=\mu_{L_{3}}(\mathrm{H} / \mathrm{Pt})-\mu_{L_{3}}(\mathrm{Pt})$. The signature of this difference spectrum $(\Delta \mu)$ is compared with $\Delta \mu$ acquired from a similar procedure applied to theoretical results obtained with the help of full multiple scattering ab initio calculations using the FEFF8 code [5] to identify specific $\mathrm{H}$ adsorption sites on the surface of the Pt particles. These results have been combined with density functional calculations using the ADF code [6] to fully interpret the experimental data.

After a thorough analysis of hydrogen TPD data in the literature comparing $\operatorname{Pt}(111)$ data, stepped surfaces, polycrystalline $\mathrm{Pt}$, and large supported Pt particles ( $>5 \mathrm{~nm}$ ), Teliska et al. [3] identified five different features in the hydrogen TPD curves for polycrystalline $\mathrm{Pt}$, each representing a specific $\mathrm{H}$ adsorption site. Five features were also found in the current voltage (CV) curves obtained in an electrochemical cell using 3-5 nm Pt clusters supported on carbon as electrode material. Teliska et al. [3] used the Pt $L_{3}$ Delta XANES signatures on these latter clusters to identify the five adsorption sites. These adsorption sites in order of increasing adsorption bond strength, $\Delta G=\Delta H-T \Delta S$, are ontop $\mathrm{H}$ near edges, $n$-fold $\mathrm{H}$ and delocalized $\mathrm{H}$ on the faces, and $n$-fold $\mathrm{H}$ and delocalized $\mathrm{H}$ near Pt edges, as summarized on the left side of Fig. 1. Because both the applied potential and temperature can be varied in electrochemistry, the $\Delta H$ and $\Delta S$ for $\mathrm{H}$ adsorption in the two primary absorption sites ( $n$-fold on faces and $n$-fold near edges) have been obtained from the CV curves [7]. The $\Delta H$ values obtained from these studies are comparable to those obtained from hydrogen TPD studies in the gas phase and from theoretical calculations. This strongly suggests that the $\mathrm{H}$ binding sites in an electrolyte and in the gas phase are comparable [8].

By using the Delta XANES technique described above and applying DFT calculations on Pt model clusters, the influence of the acid/base properties of the support on the chemisorption properties of hydrogen on intermediate Pt particles $(2.5>d>$ $1 \mathrm{~nm}$ ) has been elucidated by Oudenhuijzen et al. [4]. These authors showed that the $\mathrm{Pt}-\mathrm{H}$ bond strength is greater on ionic supports (basic oxides with electron-rich $\mathrm{O}$ atoms), resulting in a higher hydrogen coverage compared with covalent supports (acidic oxides with electron-poor $\mathrm{O}$ atoms). Depending on the temperature and ambient $\mathrm{H}_{2}$ pressure, on the $\mathrm{Pt} n$-fold sites $\mathrm{H}$ is found near cluster edges and/or corners on basic supports and in the atop position near cluster edges/corners, with lower adsorption energy, on acidic supports. Based on these results, a three-site model has been proposed [4] for intermediate-sized Pt clusters in the gas phase, with the binding energy increasing in the following order: ontop $\mathrm{H}$ and $n$-fold $\mathrm{H}$ on faces, $n$-fold near the edges, and atop; these are summarized in the center of Fig. 1. The temperature, hydrogen pressure, and ionicity of the support determine the $\mathrm{H}$ coverage of each site and consequently which type of site is available for hydrogen dissociation.

The results obtained on $\operatorname{Pt}(111)$ single-crystal surfaces and the large Pt particles (3-5 nm) supported on carbon used as

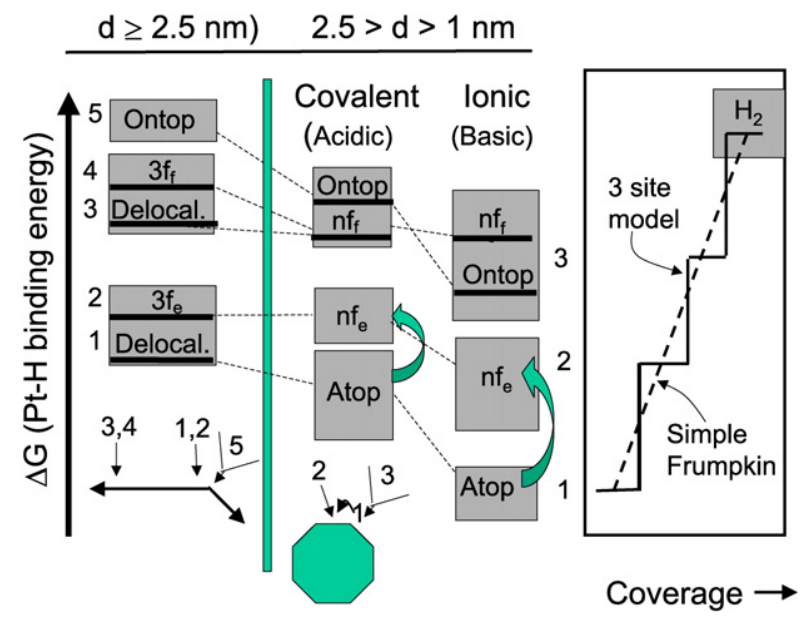

Fig. 1. Left side and center: schematic illustration of the 5 or 3 different $\mathrm{H}$ binding sites identified previously as discussed in the text, and how they correlate between large and intermediate size particles. Right side: schematic illustration of a simple Frumkin isotherm model which assumes $\Delta G=\Delta G^{0}+g \theta$, where $g$ represents the decrease in Gibbs free energy with increasing coverage due to lateral interactions $(\cdots)$, and three-site model utilized in this work which assumes a Langmuir isotherm (i.e., non-changing $\Delta G$ with coverage) but with three different bonding sites as noted (-). The arrows in all cases indicate the atop $/ n$-fold rearrangement that arises due to lateral interactions.

electrodes [3] (see the left side of Fig. 1) can be correlated with the data obtained on smaller supported Pt particles $(2.5>d>$ $1 \mathrm{~nm}$ ) (see center of Fig. 1), such as those used in catalysis [4]. The changeover of the strongest bonding site from delocalized $\mathrm{H}$ as found on $\mathrm{Pt}(111)$ single crystals and $\mathrm{Pt} / \mathrm{C}$ electrodes to atop $\mathrm{H}$ as detected on the much smaller Pt particles with sharper corners is due to the decreasing Pt coordination at these corners [4]. Delocalized $\mathrm{H}$ arises when the atop, bridged, and $n$-fold sites have comparable energy as on single crystal surfaces, so the $\mathrm{H}$ can decrease its zero-point vibrational energy by delocalizing over these three sites. Near sharp corners as on small metal particles, the atop sites have increased binding energy, so the $\mathrm{H}$ prefers the atop sites.

Direct experimental proof for the influence of the support ionicity on the $\mathrm{H}$ coverage has been obtained from hydrogen chemisorption experiments on Pt particles dispersed in zeolite $\mathrm{NaY}$, where the ionicity of the support oxygen is tuned by exchange of $\mathrm{Na}$ with different types of cations $\left(\mathrm{H}^{+}, \mathrm{Mg}^{2+}\right.$, $\mathrm{La}^{3+}$ ) [9]. DFT calculations [4,10] show that the $\mathrm{Pt}_{\mathrm{sp}}$ orbitals are important for $\mathrm{H}$ bonding, and that the rearrangement of the Pt 6s and 6p interstitial bond orbitals (IBO) with change of the support ionicity can explain these different $\mathrm{Pt}-\mathrm{H}$ bonding properties.

In this work we correlate Pt $L_{2,3}$ XANES data, H/M chemisorption, and TPD data to elucidate the changes of $\mathrm{H}$ coverage on Pt particles (average Pt particle size, $0.8-1.2 \mathrm{~nm}$ ) as a function of pressure, temperature, and support ionicity (Pt/H-USY vs Pt/NaY and Pt/H-LTL vs Pt/K-LTL). A threesite adsorption model, developed using a Langmuir isotherm and three different $\mathrm{H}$ adsorption sites (as summarized in the right side of Fig. 1), will be shown to account for the variation in coverage with change in $T, P$, and support conditions as described above. To fit the $\mathrm{H} / \mathrm{M}$ data, a $\mathrm{H}_{2}$ physisorption isotherm 
also may be included. The three $\mathrm{H}$ adsorption sites are, in order of increasing bond strength: ontop/ $n$-fold faces, $n$-fold edges, and atop $\mathrm{H}$ (see the center of Fig. 1). The $n$-fold face and ontop $\mathrm{H}$ sites are merged into one type, denoted simply as ontop bonded $\mathrm{H}$, and the $n$-fold edge $\left(n \mathrm{f}_{\mathrm{e}}\right)$ simply as $n \mathrm{f}$ in this work. The results from this work indicate that three adsorption sites with three different $\Delta G$ values and Langmuir isotherms can account for the changes in $\mathrm{H}$ coverage as a function of pressure, temperature, and support ionicity. The ramifications of these observations for the catalytic properties of supported Pt particles will be discussed.

\section{Methods}

\subsection{Experimental}

Details about the preparation of the Pt/LTL catalysts, composition of the supports, TPD experiments, and EXAFS data collection and analysis are given elsewhere [11-13]. The K/Al molar ratios of the acidic Pt/H-LTL and basic Pt/K-LTL were 0.34 and 1.05 , respectively. The average Pt-Pt EXAFS coordination number was around 4 , pointing to an average Pt particle diameter of $0.8 \mathrm{~nm}$.

\subsubsection{Preparation and characterization of the Pt particles dispersed in $Y$ zeolite}

The NaY and $\mathrm{NH}_{4}$-USY (LZY 84) supports were obtained from commercial zeolite powders [9]. Highly dispersed Pt particles were introduced inside the zeolite pores by applying a very careful synthesis procedure to obtain a narrow particle size distribution. The preparation and characterization of both catalysts is described elsewhere [9]. In short, an aqueous solution of $\mathrm{Pt}\left(\mathrm{NH}_{3}\right)_{4}\left(\mathrm{NO}_{3}\right)_{2}$ (Aldrich), containing an amount of Pt leading to a $1 \mathrm{wt} \%$ loading in the zeolite, was injected on the dry support in static vacuum. The sample was then heated with a ramp of $0.2^{\circ} \mathrm{C} / \mathrm{min}$ from 150 to $300^{\circ} \mathrm{C}$ and calcined at $300^{\circ} \mathrm{C}$ for $1 \mathrm{~h}$. For Pt/H-USY, a final temperature of $350^{\circ} \mathrm{C}$ was used for calcination to remove ammonia from the acid sites of $\mathrm{NH}_{4}$ USY to obtain $\mathrm{Pt} / \mathrm{H}-\mathrm{USY}$. After calcination and reduction at $300{ }^{\circ} \mathrm{C}$, the sample was cooled to room temperature in flowing hydrogen, flushed with a high flow of $\mathrm{N}_{2}$, and finally passivated by adding a small flow of $\mathrm{O}_{2}$ into the flowing $\mathrm{N}_{2}$.

In an earlier study, similar samples were characterized by HRTEM, hydrogen chemisorption at RT and EXAFS [9]. The average $\mathrm{Pt}$ particle size for $\mathrm{Pt} / \mathrm{H}-\mathrm{USY}$ and $\mathrm{Pt} / \mathrm{NaY}$ was 1.26 and $1.14 \mathrm{~nm}$, respectively, determined from the HRTEM data by computer analysis of the photographs. The dispersion was calculated from the averaged $\mathrm{Pt}$ particle size as 0.80 and 0.83 , respectively. Using the $\mathrm{H} / \mathrm{M}$ data and the calculated dispersion, it was possible to determine the number of adsorbed hydrogen atoms per surface $\mathrm{Pt}\left(\mathrm{H} / \mathrm{Pt}_{\mathrm{s}}\right)$ [9]. This value was much higher for the $\mathrm{Pt} / \mathrm{NaY}$ sample with a higher ionicity of the support oxygen atoms than for $\mathrm{Pt} / \mathrm{H}-\mathrm{USY}$, as mentioned in Section 1. The $\mathrm{Pt} / \mathrm{NaY}$ sample used in this work was prepared similarly but was not exactly the same as that used previously [9].

\subsubsection{TPD}

$\mathrm{H}_{2}$ TPD experiments were performed on the Pt/LTL catalysts after initial reduction in $\mathrm{H}_{2}$ at $300^{\circ} \mathrm{C}$. The desorption was programmed at a rate of $10^{\circ} \mathrm{C} / \mathrm{min}$ to $700^{\circ} \mathrm{C}$ in flowing $\mathrm{N}_{2}$. The $\mathrm{H}_{2}$ and $\mathrm{N}_{2}$ were purified by passing them over oxygen and hydrocarbon traps. Cryogenic traps containing $5 \AA$ molecular sieve were placed directly before and after the furnace for water trapping. Desorbed gases were monitored by a thermal conductivity detector and periodically checked by independent gas chromatographic or mass spectrometry analyses for $\mathrm{H}_{2}$. Full details have been provided previously [12].

\subsubsection{Hydrogen chemisorption}

Hydrogen chemisorption measurements were performed in a conventional static volume apparatus (Micromeritics ASAP 2010C). The samples were first dried under evacuation at $100{ }^{\circ} \mathrm{C}$ overnight, then reduced in pure $\mathrm{H}_{2}$ at $300^{\circ} \mathrm{C}$ for $1 \mathrm{~h}$ (ramp rate, $5^{\circ} \mathrm{C} / \mathrm{min}$ ). The samples were evacuated at this temperature for $0.5 \mathrm{~h}$, and then cooled in vacuum to the temperature at which the $\mathrm{H}_{2}$ adsorption was to be determined. The absolute amount of adsorbed $\mathrm{H}_{2}$ is determined from the decrease in pressure when adding a fixed volume of $\mathrm{H}_{2}$ to a known volume containing a known amount of catalyst. The H/Pt ratios are obtained based on the adsorbed amounts of hydrogen determined with this isotherm by extrapolation of the linear part to zero pressure. After the first $\mathrm{H}_{2}$ adsorption isotherm was obtained, the sample was evacuated at the same temperature for $10 \mathrm{~min}$ to remove weakly adsorbed $\mathrm{H}_{2}$, after which $\mathrm{H}$ adsorption was performed again to obtain the second isotherm. After the second isotherm was obtained, the sample was evacuated at $300^{\circ} \mathrm{C}$ once again, before hydrogen adsorption was carried out at the next elevated temperature via the same procedure. In this way, a series of first and second $\mathrm{H}$ isotherms as a function of temperature were obtained. The following series of temperatures was used: $35,75,100,150$, and $200{ }^{\circ} \mathrm{C}$.

The first hydrogen adsorption isotherm obviously reflects the total $\mathrm{H}$ adsorption (i.e., physisorption and chemisorption) on the samples. Evacuation removes a fraction of the adsorbed $\mathrm{H}$ (weakly chemisorbed $\mathrm{H}$ and physisorbed $\mathrm{H}_{2}$ ), leaving only the strongly bound hydrogen still on the surface of the Pt particle. Thus, the second isotherm reflects the additional weakly chemisorbed and physisorbed $\mathrm{H}$ which adsorbs at each $T$. The difference between these two isotherms is relatively constant with $P$, as shown elsewhere [9], and reflects the amount of strongly bound $\mathrm{H}$ remaining on the surface at the temperature of the $\mathrm{H} / \mathrm{M}$ experiment and the vacuum pressure used before beginning the second isotherm. We use the difference between the first and second isotherms to obtain information on the strongly bound $\mathrm{H}$ in $\mathrm{NaY}$ zeolite.

\subsubsection{XAFS spectroscopy}

X-ray absorption data were collected at the $\mathrm{Pt} L_{3}$ and $L_{2}$ edge using beamline X1.1 of the HASYLAB synchrotron (Hamburg, Germany) equipped with a $\mathrm{Si}(311)$ crystal. The monochromator was detuned to $50 \%$ of maximum intensity. All measurements were done in transmission mode using ion chambers filled with a $\mathrm{N}_{2} / \mathrm{Ar}$ mixture to have an X-ray absorbancy of 
$20 \%$ in the first ion chamber and $80 \%$ in the second ion chamber. At the Pt $L_{3}$ edge $(11564 \mathrm{eV})$, the estimated resolution was $2 \mathrm{eV}$. To decrease low- and high-frequency noise as much as possible, an acquisition time of $0.5 \mathrm{~s}$ for the EXAFS data was used, with a gradual increase to $1.5 \mathrm{~s}$ at high photon energy, and three scans were averaged.

The samples were pressed into self-supporting wafers (calculated to have an absorbency of 2.5) and placed in a controlled atmosphere cell operated at $1 \mathrm{~atm}$ [14]. The samples were dried in the cell in flowing $\mathrm{He}$ for $60 \mathrm{~min}$ at $150{ }^{\circ} \mathrm{C}$. The $\mathrm{Pt} / \mathrm{Y}$ samples were then reduced in flowing hydrogen at $300^{\circ} \mathrm{C}$ (heating rate, $\left.5^{\circ} \mathrm{C} / \mathrm{min}\right)$ for $1 \mathrm{~h}$ and cooled to room temperature $\left(25^{\circ} \mathrm{C}\right)$ in flowing hydrogen, after which spectra were taken in flowing $\mathrm{H}_{2}$. The samples were then heated in flowing $\mathrm{H}_{2}$ to the next higher temperature $\left(100,200,300\right.$, and $\left.400^{\circ} \mathrm{C}\right)$, where again the spectra were taken. After reaching the highest temperature $\left(400{ }^{\circ} \mathrm{C}\right)$ in flowing $\mathrm{H}_{2}$, the samples were cooled again in flowing $\mathrm{H}_{2}$ to room temperature, followed by an evacuation for $1 \mathrm{~h}$. XAFS spectra were again obtained in vacuum at room temperature and after heating to the next-higher temperature. The former sequence of XAFS data represents the Pt samples with hydrogen chemisorbed at a particular temperature $(\mathrm{H} / \mathrm{Pt})$, and the latter sequence of data represents the Pt samples under vacuum at the same temperature $(\mathrm{Pt})$ with the evacuation treatment at room temperature as the first treatment.

\subsection{Model for hydrogen chemisorption}

The adsorption of hydrogen can be described with a Frumkin adsorption isotherm [15], by assuming that the Gibbs free energy of hydrogen adsorption is linear with $\mathrm{H}$ coverage $\left(\theta_{\mathrm{H}}\right)$. This leads to the following equilibrium constant:

$K_{\mathrm{H}}=\frac{\theta_{\mathrm{H}}^{2}}{P_{\mathrm{H}_{2}}\left(1-\theta_{\mathrm{H}}\right)^{2}}=e^{-\left(\Delta G_{\mathrm{H}}^{0}+g_{\mathrm{H}} \theta_{\mathrm{H}}\right) / R T}$.

Here $P_{\mathrm{H}_{2}}$ is the hydrogen gas pressure, $\Delta G_{\mathrm{H}}^{0}=\Delta H-T \Delta S$ is the Gibbs free energy of hydrogen adsorption (per mole of $\mathrm{H}_{2}$ ) at zero hydrogen coverage, and $g_{\mathrm{H}}$ is the hydrogenhydrogen lateral interaction constant. Because both $\Delta H$ and $\Delta S$ can change with coverage, the lateral interaction constants can be written as $g_{\mathrm{H}}=h-T s$, where $h$ and $s$ are the corresponding enthalpy and entropy interaction constants. Thus, the Frumkin adsorption isotherm implies that the hydrogen adsorption bond becomes weaker ( $\Delta G$ less negative) with increased hydrogen coverage, as shown schematically on the right side of Fig. 1. The weaker adsorption on a surface already covered with adsorbates results from either lateral interactions (directly or through the Pt substrate) or from ligand effects [16] of already adsorbed $\mathrm{H}$, weakening the interaction with additional $\mathrm{H}$.

Rearranging Eq. (1) gives the hydrogen coverage $\left(\theta_{\mathrm{H}}\right)$ per $\mathrm{Pt}$ atom at any temperature $(T)$ and hydrogen gas pressure $\left(P_{\mathrm{H}_{2}}\right)$,

$\theta_{\mathrm{H}}=\frac{P_{\mathrm{H}_{2}}^{1 / 2} e^{-1 / 2\left(\Delta G_{\mathrm{H}}^{0}+g_{\mathrm{H}} \theta\right) / R T}}{1+P_{\mathrm{H}_{2}}^{1 / 2} e^{-1 / 2\left(\Delta G_{\mathrm{H}}^{0}+\mathrm{g}_{\mathrm{H}} \theta\right) / R T}}$.

This work uses the three-site adsorption model of Oudenhuijzen et al. [4] discussed above, with ontop (ot), $n$-fold ( $n$ f), and atop (at) adsorption sites in the order of increasing $\mathrm{Pt}-\mathrm{H}$ adsorption enthalpies, as shown in Fig. 1. Within each site, $g_{\mathrm{H}}=h-T s$ is set to zero. Equation (2) now can be used to determine the coverage, $\theta_{i}$, at each site, with the total $\mathrm{H}$ coverage/Pt atom then given by

$\theta_{\mathrm{H}}=N_{\mathrm{at}} \theta_{\mathrm{at}}+N_{n \mathrm{f}} \theta_{n \mathrm{f}}+N_{\mathrm{ot}} \theta_{\mathrm{ot}}$,

where $N_{i}$ is the number of each type of site on the cluster normalized per Pt atom.

In addition to atomic $\mathrm{H}$ on the $\mathrm{Pt}$ surface, physisorbed molecular $\mathrm{H}_{2}$ will be present on the surface of the catalysts ( $\mathrm{Pt}$ and support) at the $T$ and $P_{\mathrm{H}_{2}}$ used in the $\mathrm{H} / \mathrm{M}$ experiments. To describe the physisorption of molecular $\mathrm{H}_{2}$, a Temkin isotherm [15] is introduced,

$K_{\mathrm{H}_{2}}=\frac{\theta_{\mathrm{H}_{2}}^{2}}{P_{\mathrm{H}_{2}}\left(1-\theta_{\mathrm{H}_{2}}\right)^{2}}=e^{-\left(\Delta G_{\mathrm{H}_{2}}^{0}+\alpha P_{\mathrm{H}_{2}}\right) / R T}$.

A Temkin isotherm assumes that $\Delta G$ increases (decreases in magnitude) linearly with hydrogen pressure. The Temkin isotherm is now more appropriate because it includes adsorption on many different types of sites, the metal cluster and the support. Note that $\theta_{\mathrm{H}_{2}}$ is proportional to $P_{\mathrm{H}_{2}}$ rather than $P_{\mathrm{H}_{2}}^{1 / 2}$, making $\theta_{\mathrm{H}_{2}}$ have a totally different dependence on the hydrogen pressure $P_{\mathrm{H}_{2}}$ than $\theta_{\mathrm{H}}$.

The total coverage $\theta=N_{\mathrm{H}_{2}} \theta_{\mathrm{H}_{2}}+\theta_{\mathrm{H}}$ per Pt atom now depends on several unknown parameters: $N_{i}(i=\mathrm{ot}$, at, $n \mathrm{f}$, and phys.), $\Delta H_{i}$, and $\Delta S_{i}$ for each site. It is obvious that the number of parameters must be limited to make the model practical. The entropy change for the reaction

$(1 / 2) \mathrm{H}_{2}+\mathrm{Pt}^{*} \rightarrow \mathrm{H} / \mathrm{Pt}$

has been estimated to be $0.085 \mathrm{~kJ} /(\mathrm{kmol} \mathrm{H})$ [17]. This is a perfectly reasonable result because the absolute entropy of $\mathrm{H}_{2}$ (i.e., $\left.\mathrm{H}_{2} \rightarrow 2 \mathrm{H}\right)$ is $0.13 \mathrm{~kJ} /\left(\mathrm{kmol} \mathrm{H}_{2}\right)$ [18] [or $0.065 \mathrm{~kJ} /(\mathrm{kmol} \mathrm{H})$ ], and the adsorbed atomic $\mathrm{H}$ on the surface should have relatively much smaller entropy. This value for $\Delta S$ is used for all $\mathrm{H}$ adsorption sites and twice the value $0.170 \mathrm{~kJ} /\left(\mathrm{kmol} \mathrm{H}_{2}\right)$ for the $\mathrm{H}_{2}$ physisorption. This then leaves two parameters $\left(N_{i}\right.$ and $\left.\theta_{i}\right)$ for each of the four adsorption sites (three chemisorption sites plus one physisorption site) plus the "Temkin" parameter, $\alpha$, for a total of nine parameters to reproduce the coverage over a wide range of $T$ and $P$ in the $\mathrm{H} / \mathrm{M}$ experiments.

In fitting the TPD data, the numerical derivatives, $\mathrm{d} \theta_{i} / \mathrm{d} T$, of the expressions in Eqs. (1) and (3) are used. Only six parameters are necessary, because physisorbed hydrogen does not need to be taken into account; at low pressure, the physisorbed $\mathrm{H}$ leaves well below the temperatures used in the TPD experiments.

One additional aspect must be built into the model. Gasphase TPD experiments along with vibrational spectroscopy, as well as in situ Raman probe studies in an electrochemical cell, show the existence of ontop $\mathrm{H}$, as discussed above [3]. This ontop $\mathrm{H}$ is definitely in an atop position, as indicated by both the Delta XANES signature and vibrational spectroscopy frequencies. An important question is: How can this $\mathrm{H}$ adsorb in atop sites if these very same atop sites were first filled at very low coverage? This fact indicates that the atop sites at corners 
and edges, although filled at first, become vacant again with increasing coverage. This suggests that with increasing coverage, lateral interactions force $\mathrm{H}$ to leave the atop positions. This is exactly consistent with ADF calculations on $\mathrm{H}_{n} / \mathrm{Pt}_{4}$ clusters reported by us recently $[4,10]$, which indicate that indeed the atop site is occupied for the cluster $\mathrm{H} / \mathrm{Pt}_{4}$. However, for two $\mathrm{H}$ atoms on $\mathrm{Pt}_{4}$, two $n$-fold (i.e., either twofold bridged or $n$-fold fcc) sites are preferred. This is now included in the model by assuming that for each $\mathrm{H}$ atom adsorbed in the $n$-fold site, one atop $\mathrm{H}$ moves over to a $n$-fold site. Thus the atop sites fill first; then filling of the $n$-fold sites begins with a simultaneous emptying of the atop sites, followed finally by filling of the ontop sites when the $n$-fold sites are filled. If these atop and ontop sites were exactly the same sites, then the condition that $N_{\text {ot }}=N_{\text {at }}$ might be required. However, it also might be assumed that the atop to $n$-fold site shift occurs only at certain corner or edge sites. Thus $N_{\text {at }}$ and $N_{\text {ot }}$ are allowed to vary independently. If they were to come out similar when the H/M data were fitted, then conclusions could be drawn as to the exact nature of these ontop sites (see Section 4).

Although the total coverage with chemisorbed hydrogen, $\theta_{\mathrm{H}}$, is determined by Eq. (3), the $\mathrm{H}$ may be mobile on the surface. Therefore, $\mathrm{H}$ does not necessarily stay where it was initially adsorbed, but rather may move to the most stable available sites. This mobility can be accounted for simply by moving all $\mathrm{H}$ regardless of where it was initially adsorbed to the atop sites first (having the largest $\Delta H$ ). This will lead to filling of the $n$-fold sites while at the same time gradually rearranging the $\mathrm{H}$ in atop sites to $n$-fold sites, as indicated above; eventually, all available ontop sites having the smallest $\Delta H$ will be filled. In this simplified model, $\mathrm{H}$ mobility does not affect the total $\mathrm{H}$ coverage, but affects only the maximum coverage of each type of site, namely $N_{i}$. Therefore, the $N_{i}$ 's in Eq. (3) do not necessarily indicate the average total number of each type of site available on the clusters, but rather indicate the maximum coverage of each type of site during the uptake of $\mathrm{H}_{2}$. Thus a $N_{i}$ of 0.5 means that only about $1 / 2$ of these types of sites fill with $\mathrm{H}$, at which point lateral interactions force the $\mathrm{H}$ into the next site with lower energy.

It will be shown below that the $N_{i}$ 's are dependent on either uptake or desorption of $\mathrm{H}_{2}$. For instance, in TPD experiments or in the XANES data, the temperature is raised either in vacuum or in flowing $\mathrm{H}_{2}$, leading to desorption of $\mathrm{H}$ and thereby emptying sites. In contrast, in hydrogen chemisorption experiments, $\mathrm{H}$ uptake is observed with increasing pressure at constant temperature, beginning with a clean surface. The dependence of $N_{i}$ on uptake/desorption can be attributed to the kinetics of the rearrangement and produces a hysteresis in the site filling process, as discussed more fully below.

\subsection{Delta XANES technique}

It is well known even from early work that the Pt $L_{3}$ XANES is sensitive to the adsorption of $\mathrm{H} \mathrm{[19-22].} \mathrm{To} \mathrm{isolate} \mathrm{and} \mathrm{iden-}$ tify these rather small changes, difference spectra $\Delta \mu$ are obtained by taking the difference between the $L_{3}$ spectra with and without $\mathrm{H}, \Delta \mu_{L_{3}}=\mu_{L_{3}}(\mathrm{H} / \mathrm{Pt})-\mu_{L_{3}}(\mathrm{Pt})$, with $\mu_{L_{3}}(\mathrm{H} / \mathrm{Pt})$ the $L_{3}$-edge spectrum in the presence of $\mathrm{H}_{2}$ and $\mu_{L_{3}}(\mathrm{Pt})$ the $L_{3}$-edge spectrum in vacuum. Because the absorption $\mu$ equals $\mu_{0}(1+\chi)$, the total change can be expressed as [2]

$$
\begin{aligned}
\Delta \mu_{L_{3}} & =\mu_{L_{3}}(\mathrm{H} / \mathrm{Pt})-\mu_{L_{3}}(\mathrm{Pt}) \\
& =\Delta \mu_{0}+\Delta\left(\mu_{0} \chi_{\mathrm{Pt}-\mathrm{Pt}}\right)+\mu_{0, \mathrm{H} / \mathrm{Pt}} \chi_{\mathrm{Pt}-\mathrm{H}},
\end{aligned}
$$

where $\Delta \mu_{L_{3}}$ is the $L_{3}$-edge difference spectrum, $\mu_{L_{3}}(\mathrm{H} / \mathrm{Pt})$ is the $L_{3}$-edge spectrum in the presence of $\mathrm{H}_{2}, \mu_{L_{3}}(\mathrm{Pt})$ is the $L_{3}$-edge spectrum in vacuum, $\Delta \mu_{0}$ represents changes in the atomic $L_{3}$ XAFS with $\mathrm{H}$ coverage, $\Delta\left(\mu_{0} \chi_{\mathrm{Pt}-\mathrm{Pt}}\right)$ represents changes in the $\mathrm{Pt}-\mathrm{Pt}$ total scattering induced by $\mathrm{H}_{2}$ chemisorption, $\mu_{0, \mathrm{H} / \mathrm{Pt}}$ is free-atom $L_{3}$ absorption (including atomic XAFS) in the presence of $\mathrm{H}_{2}$, and $\chi_{\mathrm{Pt}-\mathrm{H}}$ represents additional $\mathrm{Pt}-\mathrm{H}$ scattering.

The FEFF8 code [5] was designed to calculate $\mu$ just as obtained in experiments. FEFF8 performs real-space full multiple scattering calculations using a muffin-tin potential calculated with a Hedin-Lundquist exchange correlation approximation and implements self-consistent field potentials for the determination of the Fermi level and the charge transfer. Thus $\Delta \mu$ can be calculated by performing the same $\Delta \mu$ difference as obtained experimentally. Fig. 2 shows the total $\Delta \mu$ [minus the first term in Eq. (6)] obtained from FEFF8 calculations on $\mathrm{Pt}_{6}$ clusters. As in previous work [23], the $\Delta \mu_{0}$ contribution was not included in Fig. 2 because it should be relatively small. Moreover, the $\Delta \mu_{0}$ contribution is exaggerated for these very small clusters modeled here by the FEFF8 calculations.

These FEFF8 results show the importance of changes in the Pt $L_{3}$ XANES region due to the influence of chemisorbed $\mathrm{H}$ on the Pt-Pt multiple scattering paths. When $\mathrm{H}$ atoms are adsorbed on the $n$-fold hollow sites, hydrogen weakens the Pt-Pt bonding for $\mathrm{Pt}$ atoms beneath the $\mathrm{H}$ adsorption site [the second term on the right in Eq. (6)]. This bond weakening has been called d-electron frustration by Feibelman and Hamann [24], and Pt-Pt destabilization by Papoian et al. [25]. The theoretically obtained fingerprints for atop and $n$-fold $\mathrm{H}$, as shown in Fig. 2, have been experimentally confirmed by Teliska et al. [3] and Oudenhuijzen et al. [4].

The experimental XANES data have to be carefully aligned before taking the differences as indicated in Eq. (6). This align-

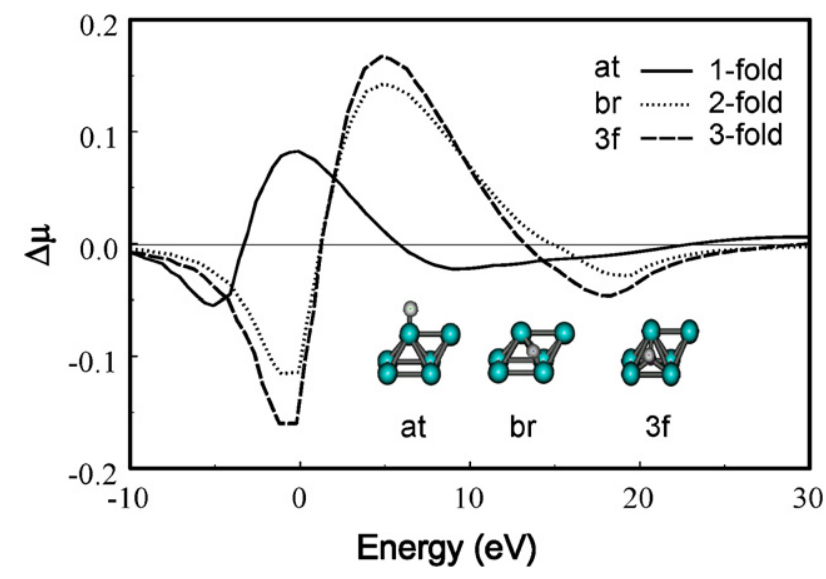

Fig. 2. Previously reported $\Delta \mu$ theoretical signatures obtained from FEFF8 calculations on the clusters indicated for atop, 2-fold bridged, and $n$-fold fcc $\mathrm{H}$. 
ment procedure has been carefully outlined previously [22]. First, the zero of energy is set to the energy that falls at 0.6 in both the normalized $\mu_{L_{2}}(\mathrm{H} / \mathrm{Pt})$ and $\mu_{L_{2}}(\mathrm{Pt})$ spectra. Then the EXAFS features in each of the $\mu_{L_{2}}$ and corresponding $\mu_{L_{3}}$ spectra are aligned using a computer routine that minimizes the square of the difference $\mu_{L_{3}}-\mu_{L_{2}}$ in an energy range usually between 30 and $100 \mathrm{eV}$ above the edge. This energy range has been varied some in our previous work, depending on the data [4]. This entire energy alignment procedure, used in all of our previous gas-phase work, is critical to obtaining systematic $\Delta \mu$ spectra because of the large cancellations involved in the differences, leaving $\Delta \mu_{L_{3}}$ typically only around $0.03-0.06$ in magnitude.

\section{Results}

\section{1. $T P D$}

The TPD data collected on the Pt/H-LTL and Pt-K-LTL catalysts are displayed in Figs. $3 \mathrm{a}$ and $3 \mathrm{~b}$ (dashed dotted lines). A weak asymmetry at low $T$ can be observed for Pt/H-LTL (Fig. 3a). The TPD of Pt/K-LTL has shoulders at around 300 and $500 \mathrm{~K}$ (Fig. 3b). The TPD data were fitted with a sixparameter fit using Eqs. (2) and (3). The total fits are indicated in Figs. $3 \mathrm{a}$ and $3 \mathrm{~b}$ with solid lines. It can be seen that the threesite model adequately describes the TPD data. The individual components are also plotted in Figs. $3 \mathrm{a}$ and $3 \mathrm{~b}$. The negative contribution in the atop component is due to the rearrangement
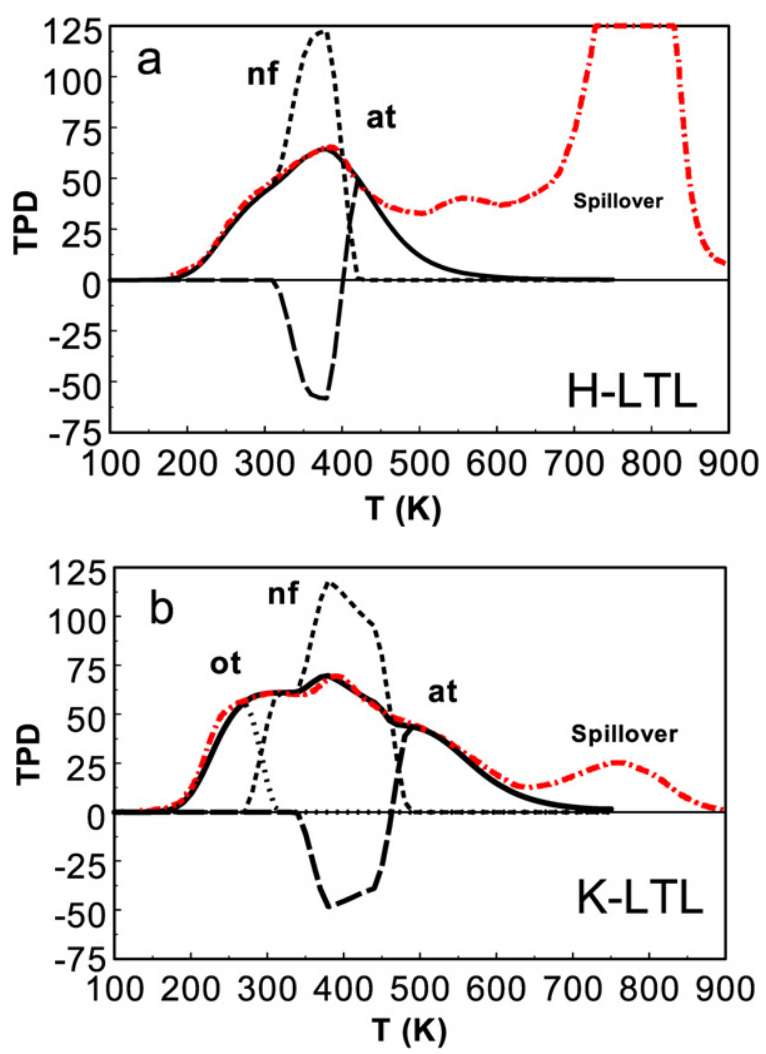

Fig. 3. TPD data collected on (a) Pt/H-LTL and (b) Pt/K-LTL (-..). Fit with three site adsorption model (6 parameters) (-). The components include the ontop (ot, $\cdots$ ), $n$-fold ( $n \mathrm{f},---$ ), and atop (at, ---).
Table 1

Summary of TPD fit parameters using derivative of Eq. (3) and 3-site model for the LTL samples

\begin{tabular}{llllll}
\hline & \multicolumn{2}{l}{ Pt/H-LTL } & & & Pt/LTL \\
\cline { 2 - 3 } \cline { 5 - 6 } \cline { 5 - 6 } & $N_{\text {sites }}$ & $\Delta H(\mathrm{~kJ} / \mathrm{mol})$ & & $N_{\text {sites }}$ & $\Delta H(\mathrm{~kJ} / \mathrm{mol})$ \\
\hline Atop & $0.32 \pm 0.05$ & $-49 \pm 2$ & & $0.35 \pm 0.05$ & $-71 \pm 2$ \\
$n$-fold & $0.52 \pm 0.05$ & $-43 \pm 2$ & & $0.51 \pm 0.05$ & $-46 \pm 2$ \\
Ontop (weak) & Not observed & & & $0.26 \pm 0.05$ & $-32 \pm 2$ \\
\hline
\end{tabular}

from $n$-fold sites to atop sites and will be further explained in Section 4. The number of filled sites per Pt surface atom and the adsorption enthalpy of each type of site are given in Table 1. It can be seen that the number of filled atop sites is lower than the number of filled $n$-fold sites for both Pt/LTL catalysts. Table 1 also shows that the $\Delta H_{i}$ values for the basic Pt/K-LTL catalyst are more negative, pointing to a stronger $\mathrm{Pt}-\mathrm{H}$ bond for each type of chemisorption site on Pt particles dispersed in a basic zeolite. The Pt-H bond strength is increasing in the order ontop $<n$-fold $<$ atop for each catalyst. Obviously, the Pt-H bond strength for the ontop site is so low for the acidic $\mathrm{Pt} / \mathrm{H}$ LTL that no hydrogen is chemisorbed on these sites in vacuum, but these sites serve as catalytic sites to dissociate $\mathrm{H}_{2}$, which then spills over to the support. The spillover peak arising from desorption of $\mathrm{H}$ from the support is present in the TPD data at high temperature and is indeed very intense for the $\mathrm{Pt} / \mathrm{H}$ LTL catalysts. These same ontop sites in the K-LTL sample also probably produce spillover, but to a lesser extent.

\section{2. $H / M$ chemisorption}

Fig. 4 shows the first isotherms for $\mathrm{Pt} / \mathrm{H}-\mathrm{USY}$ and $\mathrm{Pt} / \mathrm{NaY}$ and the least squares fits for each using the adsorption model described above for the six different temperatures of adsorption. The corresponding parameters obtained from these fits are given in Table 2. The separate components for $\mathrm{H}$ chemisorption and $\mathrm{H}_{2}$ physisorption and the separate atop, threefold, and ontop components of the $\mathrm{H}$ chemisorption for each adsorption temperature and support calculated from the fits are plotted in Figs. 1 and 2 in supplementary material.

The agreement between the fits and experiment is reasonable, considering that 150 points are fit with 9 parameters. No matter where the iterative nonlinear least squares process was started, the final result was the same, indicating these fits correspond to the true minimum. The Temkin isotherm for the physisorbed $\mathrm{H}_{2}$ was clearly required to give a reasonable fit. As expected, for physisorption, a very small $\Delta H_{\text {phys }}$ and a very large $N_{\text {phys }}$ was found for each support. $\mathrm{H}_{2}$ can physisorb not only on the Pt particles, but also on the zeolite. The Temkin isotherm shows that the value of $\Delta H_{\text {phys }}$ increased from about -4 to nearly $0 \mathrm{~kJ} / \mathrm{mol}$ (an effective decrease of $\Delta H_{\text {phys }}$ ) with increasing adsorption temperature, also consistent with its properties.

The fits in general show a curvature that is too small at low pressure. This clearly suggests that the $\Delta H$ for each site may be larger initially and then decrease with coverage (i.e., a Frumkin isotherm for each site). A Frumkin isotherm for each site would introduce at least three additional parameters ( $h_{i}$ for each site), 

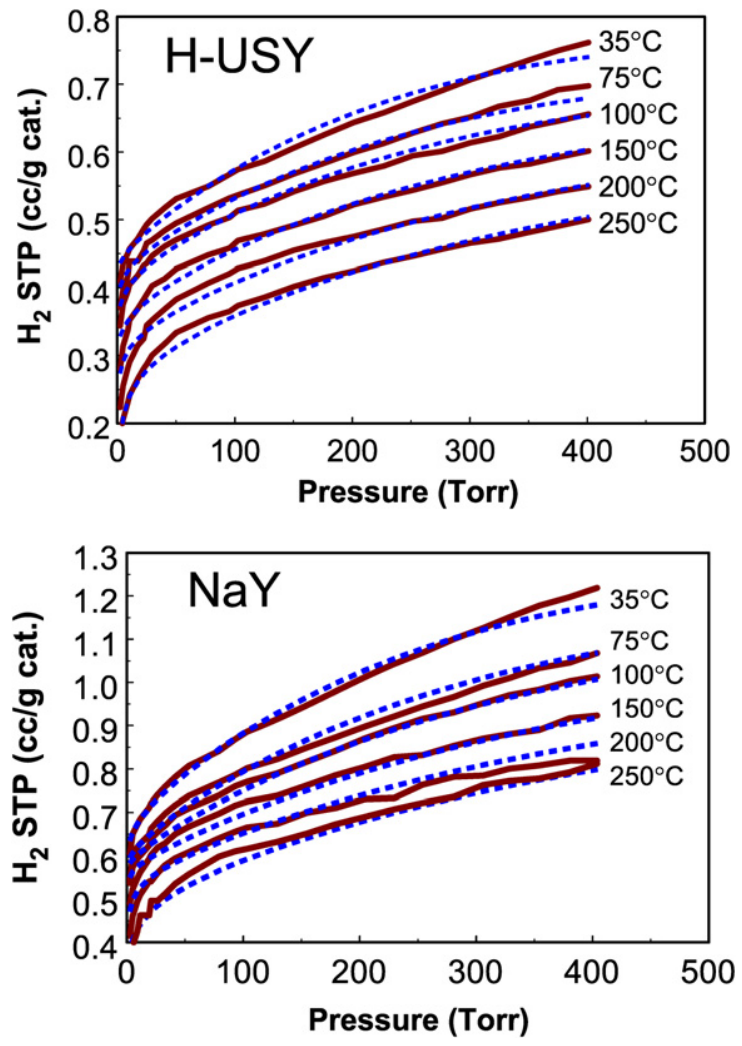

Fig. 4. Fit of the four adsorption site model (9 parameters) to the H/M chemisorption data at the temperatures indicated for $\mathrm{Pt} / \mathrm{H}-\mathrm{USY}$ and $\mathrm{Pt} / \mathrm{NaY}$.

and thus certainly would give a better overall fit. A Frumkin isotherm is much more difficult to introduce, because $\theta$ then appears on both sides of the equation [see Eq. (2)], and one must iterate to a final answer. Although a Frumkin isotherm for each individual site may ultimately prove useful, it was decided that for this work the current fits are more than adequate. The model was kept conceptually simple and the fitting procedure straightforward by applying three Langmuir isotherms for the $\mathrm{H}$ adsorption.

The sum of the $N_{i}$ magnitudes (and hence total coverage) is, of course, dependent on the volume of $\mathrm{H}_{2}$ ( $\left.\mathrm{cc} \mathrm{H} / \mathrm{H}_{\text {cat }}\right)$ assumed to be equivalent to a monolayer (ML) of $\mathrm{H}$ coverage $(1 \mathrm{H} /$ $\left.\mathrm{Pt}_{\text {surface }}\right)$ on the $\mathrm{Pt}$ surface in the chemisorption experiments. A simple calculation assuming $22,400 \mathrm{cc}$ at $\mathrm{STP} / \mathrm{mol} \mathrm{H}_{2} \times$ $\left(1 \mathrm{H}_{2} / 2 \mathrm{H}\right) \times(1 \mathrm{~mol} \mathrm{Pt} / 196 \mathrm{~g} \mathrm{Pt}) \times\left(0.8 \mathrm{Pt}_{\mathrm{s}} / \mathrm{Pt}\right) \times(1 \mathrm{~g} \mathrm{Pt} / 100 \mathrm{~g}$ catalyst $)=0.46 \mathrm{cc} \mathrm{H}_{2} / \mathrm{g}_{\text {cat }}$, where $\mathrm{Pt}_{\mathrm{s}} / \mathrm{Pt}$ is equal to the dispersion of around 0.8 for these particles determined by HRTEM [9]. Extrapolation of the nearly straightline region of the first isotherm at $35^{\circ} \mathrm{C}$ in Fig. 4 to zero pressure for $\mathrm{PT} / \mathrm{H}-\mathrm{USY}$ gives about $0.52 \mathrm{cc} \mathrm{H}_{2} \mathrm{STP} / \mathrm{g}_{\text {cat }}$, which suggest a coverage of $1.1 \mathrm{H} / \mathrm{Pt}_{\mathrm{s}}$ as determined previously [9]. We conclude in this paper that $0.5 \mathrm{cc}$ of $\mathrm{H}_{2} / \mathrm{g}_{\text {cat }}$ corresponds to about $1 \mathrm{H} / \mathrm{Pt}_{\mathrm{s}}$. The $\mathrm{H}$ coverage on $\mathrm{NaY}$ is obviously higher, because a similar extrapolation in Fig. 4 for $\mathrm{Pt} / \mathrm{NaY}$ gives approximately $0.75 \mathrm{cc} \mathrm{H} / \mathrm{g}_{\text {cat }}$, suggesting a coverage of $1.5 \mathrm{H} / \mathrm{Pt}_{\mathrm{s}}$. The difference with previous work $\left(0.94 \mathrm{cc} \mathrm{H}_{2} / \mathrm{g}_{\text {cat }}\right.$ in Ref. [9]) can be attributed to either slightly different $\mathrm{Pt}$ particle size or slightly different support ionicity. Note that the sums of the $N_{i}$ in Table 2 (equal to 1.57 for PT/H-USY and 1.42 for $\mathrm{Pt} / \mathrm{NaY}$, respectively) are much higher than 1.1 for $\mathrm{Pt} / \mathrm{H}-\mathrm{USY}$ and around 1.5 for $\mathrm{Pt} / \mathrm{NaY}$. This suggests simply that the weakly bonded ontop sites are not fully covered at low pressure (i.e., the point reached by the extrapolation) for $\mathrm{Pt} / \mathrm{H}-\mathrm{USY}$ as already indicated in the TPD results. This will become more clear on examining model results to be given in Figs. 10 and 11 below.

Table 2 indicates that the $\Delta H_{i}$ for the atop sites in $\mathrm{Pt} / \mathrm{NaY}$ could not be determined from the fit. This is because over the entire $T$ and $P$ range of the $\mathrm{H} / \mathrm{M}$ chemisorption data, the atop $\mathrm{H}$ remained at nearly full coverage. This can be seen in Fig. 2 in supplementary material, which shows nearly a constant coverage for all $T$ and $P$ for the atop $H$. Therefore, the fit is completely insensitive to $\Delta H_{\text {at }}$. Thus, the only information from the fit for $\Delta H_{\mathrm{at}}$ on $\mathrm{Pt} / \mathrm{NaY}$ is that it is larger than or equal to $80 \mathrm{~kJ} / \mathrm{mol}$ (see Section 4). For similar reasons, the $\Delta H_{\mathrm{ot}}$ and $N_{\text {ot }}$ parameters for the ontop (weakly bonded) $\mathrm{H}$ in $\mathrm{Pt} / \mathrm{H}-\mathrm{USY}$ have very large uncertainties, because the ontop sites make a very small contribution over the $T$ and $P$ of the $\mathrm{H} / \mathrm{M}$ data.

\subsection{Delta XANES}

With increasing temperature significant changes both in amplitude and shape can be observed in the raw data of the Pt $L_{2}$ and $L_{3}$ edge of Pt/H-USY measured in flowing hydrogen and in vacuum (see Fig. 3 in supplementary materials). The changes can be observed in more detail by plotting the difference spectra $\Delta \mu=\mu(T, P)-\mu(673 \mathrm{~K}$, vac $)$ for both the $L_{2}$ and $L_{3}$ edges (Fig. 5, Pt/H-USY; Fig. 6, Pt/NaY). The spectra obtained at $673 \mathrm{~K}$ in vacuum were used as reference in all cases, assuming that under these conditions almost all $\mathrm{H}$ is removed from the $\mathrm{Pt}$ surface. With increasing temperature, a strong reduction in the

Table 2

Summary of H/M chemisorption fit parameters using Eq. (3) and the three-site model for the NaY and HUSY samples

\begin{tabular}{llllll}
\hline & Pt/H-USY & & & Pt/NaY \\
\cline { 2 - 3 } & $N_{\text {sites }}$ & $\Delta H(\mathrm{~kJ} / \mathrm{mol})$ & & $N_{\text {sites }}$ & $\Delta H(\mathrm{~kJ} / \mathrm{mol})$ \\
\hline Atop & $0.62 \pm 0.02$ & $-57 \pm 0.5$ & $0.55 \pm 0.07$ & $<(-80)^{\mathrm{a}}$ \\
$n$-fold & $0.22 \pm 0.02$ & $-40 \pm 1$ & $-23 \pm 10$ & $0.31 \pm 0.05$ & $-53 \pm 1$ \\
Ontop (weak) & $0.73 \pm 3.0$ & -3.8 to $0( \pm 0.6)^{\mathrm{d}}$ & $0.56 \pm 0.070$ & $-32 \pm 1$ \\
Physisorbed $^{\mathrm{b}}$ & $3.6 \pm 0.6 \times 10^{8 \mathrm{c}}$ & $3.5 \pm 0.3 \times 10^{8}$ & -5.2 to $-2.2( \pm 0.4)^{\mathrm{d}}$ \\
\hline
\end{tabular}

a The Temkin parameter $\alpha=3.6 \pm 0.3$ for PT/H-USY and $3.0 \pm 0.3$ for Pt/NaY.

b Could not be determined using $\mathrm{H} / \mathrm{M}$ fit to first isotherm; see text.

c Large uncertainty is due to very small contribution over experimental H/M range.

d Due to Temkin isotherm $\Delta H$ physisorbed is different for each adsorption temperature and is given for the lowest and highest adsorption temperature. 

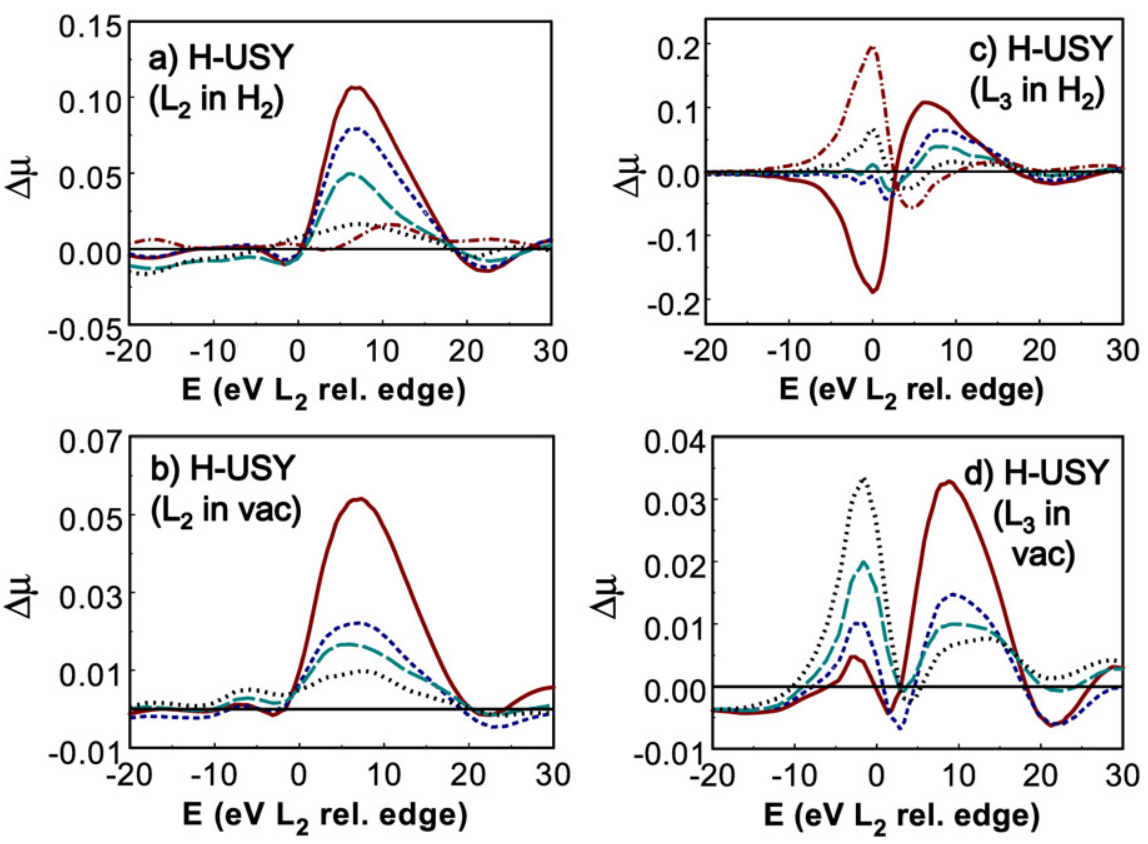

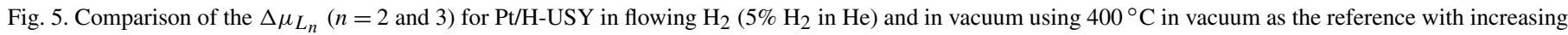
$T$ at 25 (solid), 100 (short dashed), 200 (long dashed), 300 (dotted), and $400{ }^{\circ} \mathrm{C}$ (dot-dashed).
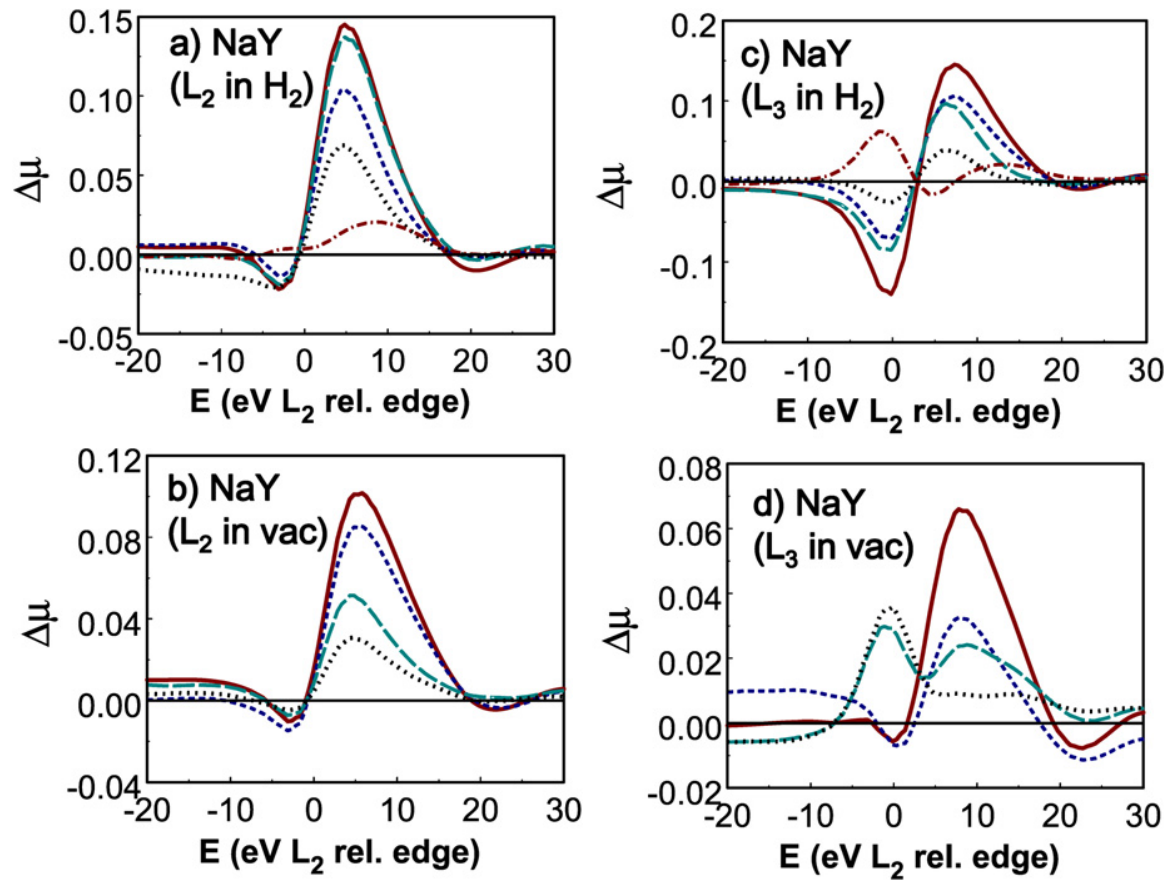

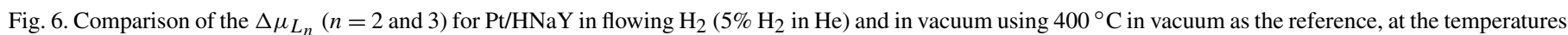
and lines types given in Fig. 5 (intensity increasing with $T$ in each case).

intensity of the $\Delta \mu_{L_{2}}$ spectra for both $\mathrm{Pt} / \mathrm{H}-\mathrm{USY}$ and $\mathrm{Pt} / \mathrm{NaY}$ is observed (see Figs. 5a and 5b, 6a and 6b). This is indicative of desorption of $\mathrm{H}$ from the $\mathrm{Pt}$ surface with increasing temperature. Moreover, using the signatures of the $\Delta \mu_{L_{3}}$ spectra (see Fig. 2), information about the type of Pt site (atop, $n$-fold, or ontop) on which hydrogen is chemisorbed can be obtained. It can be seen that with increasing temperature in flowing hydrogen (see Figs. 5c and 6c), the signature changes from an $n$-fold adsorption site at room temperature to an atop adsorption site at
$400{ }^{\circ} \mathrm{C}$ for both $\mathrm{Pt} / \mathrm{H}-\mathrm{USY}$ and $\mathrm{Pt} / \mathrm{NaY}$. An important difference between the two catalysts can be observed; the switchover from $n$-fold to atop occurs in flowing hydrogen at a lower temperature for Pt/H-USY. Moreover, a comparison of Figs. 5d and $6 \mathrm{~d}$ shows that by heating in vacuum this transition occurs at an even lower temperature for Pt/H-USY.

In some sense, the $\Delta \mu_{L_{2}}$ and $\Delta \mu_{L_{3}}$ differences complement each other. The $\Delta \mu_{L_{2}}$ show nearly the exact same trend as the $\Delta \mu_{L_{3}}$, except the magnitude below $3 \mathrm{eV}$ is greatly reduced be- 


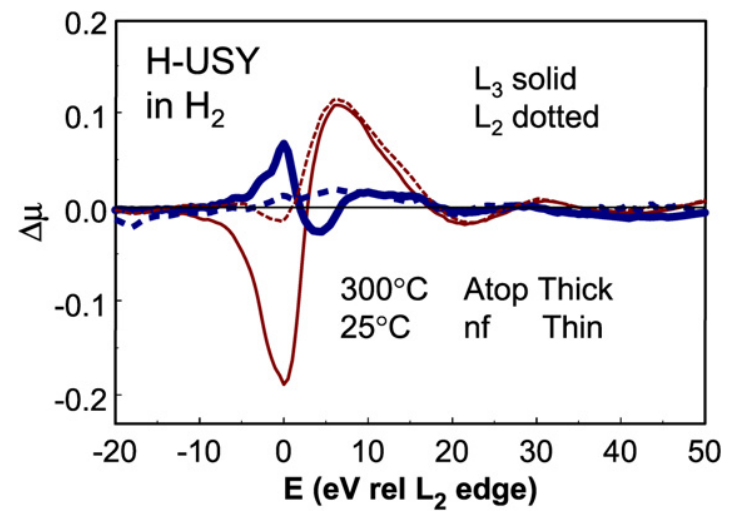

Fig. 7. Comparison of $\Delta \mu_{L_{2}}$ and $\Delta \mu_{L_{3}}$ for Pt/H-USY at 25 and $300^{\circ} \mathrm{C}$ showing that $\Delta \mu_{L_{2}}$ reflects primarily the $n$-fold $\mathrm{H}$ coverage, and the $\Delta \mu_{L_{3}}$ shape reflects the binding site.

cause of the arctangent cutoff (i.e., the Fermi level is effectively higher in the $L_{2}$ spectra). The "white line" is usually bigger in the $L_{3}$ XANES compared with the $L_{2}$ for exactly the same reason. Fig. 7 shows the remarkable similarity in the data above $3 \mathrm{eV}$ ( $8 \mathrm{eV}$ for the atop site), even though the data for obtaining these results are all different; that is, the references for the $L_{2}$ and $L_{3}$ are different, and of course the data are different at each temperature. Thus Fig. 7 serves as a confirmation of the precision and signature obtained at each temperature.

Fig. 7 also shows that the amplitude of the $8-\mathrm{eV}$ feature in $\Delta \mu_{L_{2}}$ is the best for determining the $\mathrm{H}$ coverage, and thus this feature in the $L_{2}$ data is used for this purpose. The $\Delta \mu_{L_{3}}$ data can be used to monitor the signature change from $n$-fold to atop $\mathrm{H}$ binding sites. This can be realized by defining a shape parameter $(R)$ as the ratio between the defined intensities $I_{1}$ (around $-1 \mathrm{eV}$ ) and $I_{2}$ (at $8 \mathrm{eV}$ ) (see Fig. 8a). This ratio will go from around -1 (pure $n$-fold $\mathrm{H}$ ) to large positive values of up to 7 (for mostly atop $\mathrm{H}$ ). The solid line in Fig. 8a represents a pure $n$-fold signature with $R$ value of -1 ; the dotted line represents a pure atop signature. An equal occurrence of $n$-fold and atop sites is represented by $R=0$. This value of $R$ can now be used to determine at which hydrogen coverage or at which temperature the transition from $n$-fold to atop occurs.

Fig. $8 \mathrm{~b}$ presents a plot of $R$ versus $I_{2}\left(L_{2}\right)$ and shows that the $n$-fold to atop transition occurs at a lower coverage and at a different rate on $\mathrm{Pt} / \mathrm{H}-\mathrm{USY}$ compared with $\mathrm{Pt} / \mathrm{NaY}$. It occurs for $n$-fold coverage ( $I_{2}$ intensity) in the range of $0.0-0.02$ on $\mathrm{Pt} / \mathrm{H}-\mathrm{USY}$ compared with $0.0-0.06$ on $\mathrm{Pt} / \mathrm{NaY}$. We discuss these important results further below. Both the results in flowing $\mathrm{H}_{2}$ and in vacuum fall on the same plot, as might expect be expected, but the results are different for Pt/H-USY compared with $\mathrm{Pt} / \mathrm{NaY}$.

Fig. 9a shows the $\mathrm{H}$ coverage ( $I_{2}$ intensity) dropping with increasing temperature, both in flowing hydrogen and in vacuum, just as would be expected. Using the values for the $n$-fold coverage where the transition to atop occurs (horizontal lines in Fig. 9a), it can be seen that both in flowing $\mathrm{H}_{2}$ and in vacuum, the transition occurs at a lower temperature on the Pt/H-USY sample. The shape parameter $R$ is plotted as a function of the temperature in Fig. 9b. This plot also shows that the rearrange-
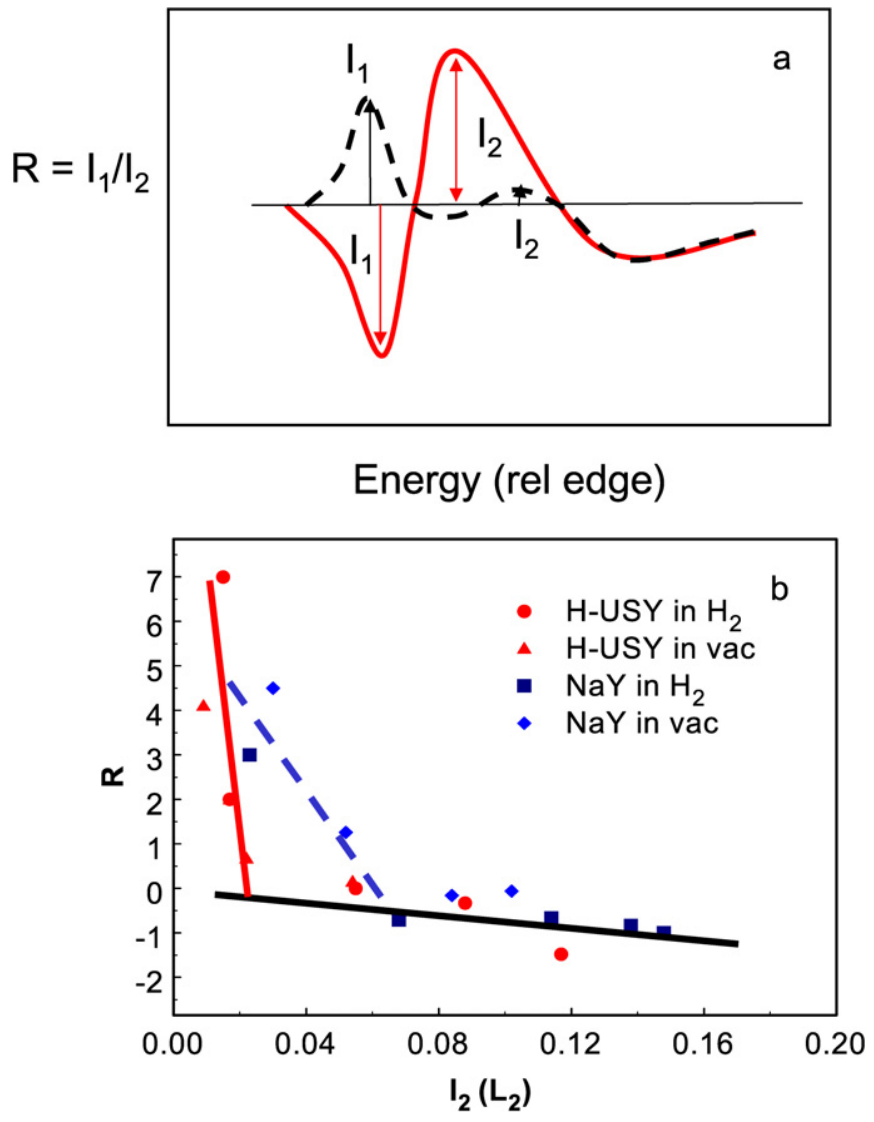

Fig. 8. (a) Definition of $I_{2}$ (the amplitude around $8-12 \mathrm{eV}$ ) reflecting the coverage of $\mathrm{H}$, and the ratio $I_{1} / I_{2}$ (the ratio of the intensity at $-1 \mathrm{eV}$ to that at 8-12 eV) reflecting the binding site. (b) Ratio $R=I_{1} / I_{2}$ vs $\Delta \mu_{L_{2}}$ intensity obtained in flowing $\mathrm{H}_{2}$ and in vacuum for PT/H-USY and Pt/NaY. Note that the points in $\mathrm{H}_{2}$ and vacuum fall on the same curves, as they should. The points where the straight lines cross indicate the coverage where the $n$-fold/atop rearrangement occurs.

ment from mostly $n$-fold to atop $\mathrm{H}(R=0)$ takes place at a lower temperature on the Pt/H-USY sample.

\section{Discussion}

\subsection{Determination of $\Delta H_{\mathrm{at}}$ in Pt/NaY from the second isotherm}

The fits to the first isotherm as described in Section 3.1 could not provide a value for the $\Delta H_{\text {at }}$ in the $\mathrm{Pt} / \mathrm{NaY}$ sample, because over the entire $T$ and $P$ range of the H/M chemisorption data, the atop $\mathrm{H}$ for this sample stayed at nearly full coverage. As indicated in Section 2.1.2, two isotherms on each sample were obtained. The difference between these isotherms, $\Delta I=$ Isotherm $_{1}-$ Isotherm $_{2}$, reflects the amount of strongly bound $\mathrm{H}$ remaining on the $\mathrm{Pt}$ at the indicated $T$ and vacuum pressure used before starting the second isotherm. Because it was not possible to obtain a value for $\Delta H_{\text {at }}$ in $\mathrm{Pt} / \mathrm{NaY}$ by fitting the first isotherm, the second isotherm data now can be used to obtain information on the in $\mathrm{Pt} / \mathrm{NaY}$.

By fitting the second isotherm obtained on $\mathrm{Pt} / \mathrm{H}-\mathrm{USY}$ using the parameters as given in Table 2, it is possible to obtain the pressure, which gives optimal agreement between the experi- 

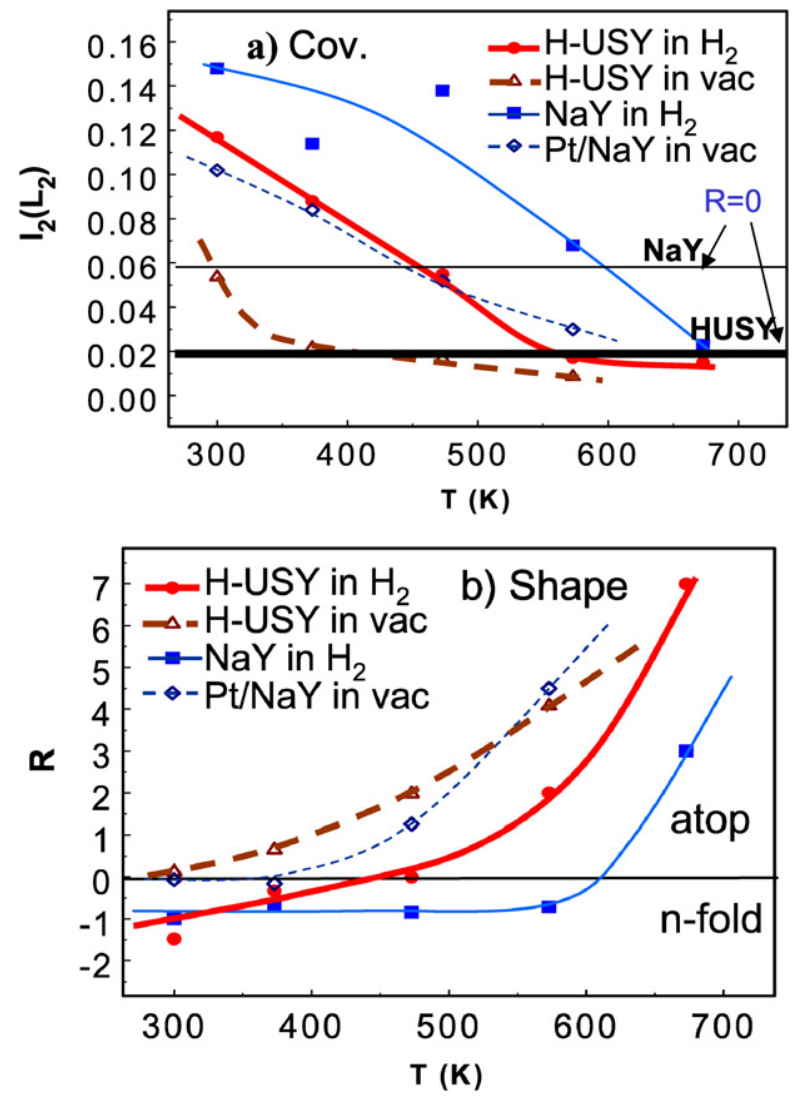

Fig. 9. Plots of $I_{2}$ (a) and the ratio $R=I_{1} / I_{2}$ (b) for Pt/H-USY and Pt/NaY in flowing $\mathrm{H}_{2}$ and in vacuum as indicated. The horizontal lines in (a) indicate the $\Delta \mu_{L_{2}}$ intensity where the $n$-fold/atop rearrangement occurs according to Fig. 8b.

mental $\Delta I$ and the calculated $H$ coverages on Pt/H-USY. Using this same pressure for the $\mathrm{Pt} / \mathrm{NaY}$, we can then estimate $\Delta H_{\text {at }}$ for $\mathrm{Pt} / \mathrm{NaY}$ (namely that value giving the best agreement with $\Delta I$ for Pt/NaY). This optimal value of $\Delta H_{\text {at }}$ is $-80 \mathrm{~kJ} / \mathrm{mol} \mathrm{H}_{2}$. Fig. 10 shows a plot of the calculated $\mathrm{H}$ coverage versus $T$ assuming a pressure of $5 \times 10^{-9}$ atm and using the parameters as given in Table 2.

\subsection{Atop to $n$-fold $H$ site rearrangement}

This work shows that it is possible to fit H/M and TPD data with a model based on the assumption of three main chemisorption sites (ontop, $n$-fold, and atop) for hydrogen on Pt. This model was derived earlier from Delta XANES data [4]. The Delta XANES results presented here show the change in signature of the $\mathrm{H}$ binding site from $n$-fold to atop (see Figs. 5 and $6 \mathrm{~d}$ ) when raising the temperature in hydrogen or vacuum. To further verify our model, it is imperative to correlate the temperature at which the transition from $n$-fold to atop occurs as found in the Delta XANES data with the temperature at which the corresponding isotherms calculated from the $\mathrm{H} / \mathrm{M}$ data show a crossover from $n$-fold to atop.

First, an important aspect needs to be discussed regarding the atop $/ n$-fold rearrangement. The XANES data were taken by raising the temperature in either flowing $\mathrm{H}_{2}$ or in vacuum (i.e., desorbing $\mathrm{H}_{2}$ ) for each succeeding temperature. Thus the

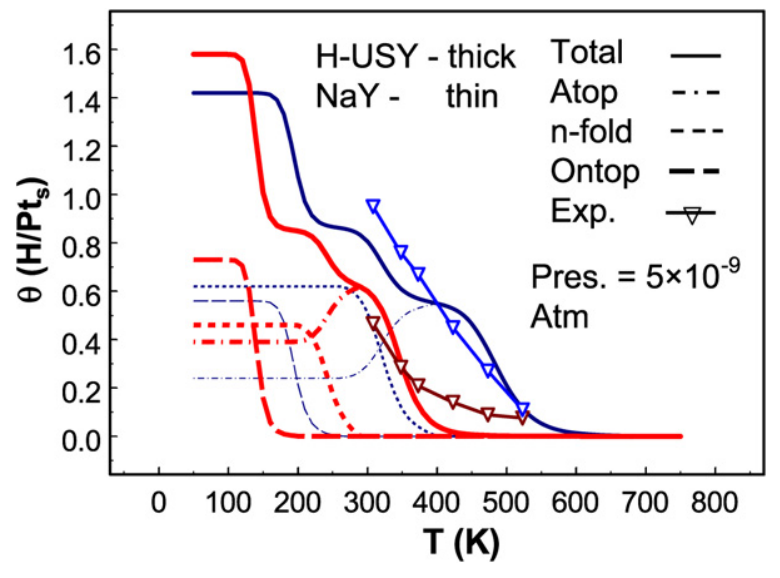

Fig. 10. Calculated coverage of the indicated $\mathrm{H}$ sites in $\mathrm{Pt} / \mathrm{H}-\mathrm{USY}$ and $\mathrm{Pt} / \mathrm{NaY}$ using the 3-site model and the parameters obtained from the H/M chemisorption fit, assuming a pressure of $5 \times 10^{-9} \mathrm{~atm}$. Also indicated is the coverage of $\mathrm{H}$ obtained by taking the difference of the first and second isotherm (Isotherm 1 - Isotherm ${ }_{2}$ ), which reflects the $\mathrm{H}$ coverage at the vacuum pressure utilized to remove the $\mathrm{H}$ after the first isotherm (nominally $5 \times 10^{-9} \mathrm{~atm}$ ).

XANES data as collected in this work reflect the $\mathrm{H}$ desorption similar to the TPD experiments. In fitting the TPD data collected on the Pt/LTL catalysts, we obtained $N_{n \mathrm{f}}$ and $N_{\text {at }}$ values of the order 0.6 and 0.3 (see Table 1 , which are different from the H/M chemisorption data around 0.3 and 0.6 as obtained for the $\mathrm{Pt} / \mathrm{Y}$ catalysts; see Table 2). Although the $\Delta H_{i}$ values for the atop and $n$-fold sites are slightly smaller (i.e., less negative) for the Pt/LTL catalysts, the range in acidbase properties of the Pt/LTL and Pt/Y samples is similar. This suggests that the difference in $N_{n \text { f }}$ and $N_{\text {at }}$ values found for the TPD and H/M are significant. These differences now can be directly correlated to the differences in type of experiment: $\mathrm{H}$ uptake in $\mathrm{H} / \mathrm{M}$ chemisorption and $\mathrm{H}$ desorption in TPD experiments.

The dominant site is the "initial" site in the experiment; that is, the $N_{\text {at }}>N_{n \mathrm{f}}$ in the $\mathrm{H}$ uptake process (H/M experiment), and the $N_{n \mathrm{f}}>N_{\text {at }}$ in H desorption (TPD or XANES). During uptake, the strongest bonded $\mathrm{H}$ in an atop site cannot move from an atop site to an $n$-fold site by itself, because this atop $\mathrm{H}$ atom is surrounded by several $n$-fold $\mathrm{H}$ atoms. It is the lateral interactions between this atop $\mathrm{H}$ and the surrounding $n$-fold $\mathrm{H}$ atoms that decreases its absolute binding energy inducing the $\mathrm{H}$ to move off the atop site. However, it cannot move off the atop site unless a nearby $n$-fold site is vacated. Thus, the atop $/ n$-fold $\mathrm{H}$ rearrangement is most probably a collective rearrangement of some small island or domain of $\mathrm{H}$ on the Pt surface. With this collective mechanism, the hysteresis effect occurs in the $\mathrm{H}$ atom rearrangement for the same reason that hysteresis occurs in magnetism. A magnetic domain flips collectively rather than each spin flipping individually, and of course this collective process also occurs in magnetism because of lateral (i.e., spin-spin) interaction. During desorption, the situation is different. With increasing $T$, the filled, weakly bonded ontop sites will become empty first. Then the filled $n$-fold sites will become empty by desorbing $\mathrm{H}$ as $\mathrm{H}_{2}$ into the gas phase. During this process, the loss in lateral interaction increases the binding energy of the atop sites, which then become filled with hydro- 
gen before all of the $n$-fold sites become empty. This is nicely illustrated in Figs. 3a and 3b. It can be seen that the atop component in the TPD data first has a negative contribution, implying an initial filling of the atop sites when the $n$-fold become empty.

Therefore, the number of filled atop sites found from analyzing the TPD data will always be lower than detected during uptake $(\mathrm{H} / \mathrm{M})$ due to the loss of chemisorbed $\mathrm{H}$ into the gas phase during desorption. Tables 1 and 2 show that the sum $N_{\text {at }}+N_{n \mathrm{f}}$ remains the same regardless of desorption/adsorption. This means that the total coverage of strongly bonded $\mathrm{H}$ is the same in both experiments (uptake vs desorption), with only the coverage at the point at which transition occurs changing.

The slower atop $/ n$-fold rearrangement with $\mathrm{H}$ coverage in the Pt/NaY sample compared with PT/H-USY (Fig. 8b) is completely consistent with the difference in the $\Delta H_{i}$ 's $(\delta \Delta H=$ $\left.\left|\Delta H_{\mathrm{ot}}-\Delta H_{n \mathrm{f}}\right|\right)$ for the $n$-fold and atop sites. For $\mathrm{Pt} / \mathrm{NaY}$, $\delta \Delta H_{\mathrm{NaY}}=27 \mathrm{~kJ} / \mathrm{mol} \mathrm{H}_{2}$ and $\delta \Delta H_{\mathrm{HUSY}}=17 \mathrm{~kJ} / \mathrm{mol} \mathrm{H}_{2}$ (see Table 2). During $\mathrm{H}$ adsorption, the atop $/ n$-fold rearrangement will occur at a particular site when the lateral interactions at that atop site increase $\Delta H_{\text {at }}$ to the point where it is comparable or larger than $\Delta H_{n \mathrm{f}}$, making the rearrangement desirable (i.e., when $\Delta H_{\mathrm{at}}+h \theta_{\mathrm{H}} \geqslant \Delta H_{n \mathrm{f}}$ or $\left|g \theta_{\mathrm{H}}\right|>|\delta \Delta H|$ ). Here $h$ is the enthalpy increase due to lateral interactions consistent with the Frumkin isotherm, as discussed in Section 2.2. Because $\delta \Delta H_{\mathrm{NaY}}>\delta \Delta H_{\mathrm{HUSY}}$, the $\mathrm{H}$ coverage must be larger to induce the rearrangement consistent with experiment.

\subsection{Comparison of the $H$ coverage determined from $H / M$ and Delta XANES results}

To make a comparison between the $\mathrm{H} / \mathrm{M}$ chemisorption and the Delta XANES data, the values for the $N_{i}$ 's obtained from the TPD experiments (Table 1) must be used to account for the hysteresis affect noted above, because the Delta XANES data were taken with increasing temperature (desorption).

Further, the $\mathrm{H}_{2}$ pressures used for the collection of the Delta XANES must be estimated in flowing $\mathrm{H}_{2}$ and in vacuum. In flowing $\mathrm{H}_{2}\left(5 \% \mathrm{H}_{2}\right.$ in $\mathrm{He}$ at $\left.1 \mathrm{~atm}\right)$, the $\mathrm{H}_{2}$ pressure can be assumed to be $0.05 \mathrm{~atm}$. Although the pressure gauge reads $1 \times 10^{-7}$ atm near the vacuum pump while taking the XANES data under vacuum, the $\mathrm{H}_{2}$ pressure inside the zeolite sample is actually much higher due to diffusion limitation in the micropores of the zeolite. A $\mathrm{H}_{2}$ pressure around $1 \times 10^{-5}$ atm is found to provide optimal agreement with the vacuum Delta XANES data and the $\mathrm{H} / \mathrm{M}$ data.

To calculate the hydrogen coverage from the $I_{2}\left(L_{2}\right)$ magnitudes obtained from the Delta XANES data, a scale factor must be determined. The scale factor $(A)$ is chosen to make $\theta_{\mathrm{H}}=$ $A^{*} I_{2}\left(L_{2}\right)$ agree optimally with the $\theta_{\mathrm{H}}$ coverages for $\mathrm{Pt} / \mathrm{NaY}$ and $\mathrm{Pt} / \mathrm{H}-\mathrm{USY}$ as calculated from the $\mathrm{H} / \mathrm{M}$ data. The quantitative comparison between the $\mathrm{H}$ coverage, $\theta_{\mathrm{H}}$, indicated from the $\mathrm{H} / \mathrm{M}$ fits and that indicated from the Delta XANES in flowing $\mathrm{H}_{2}$ is presented in Fig. 11. In addition, a quantitative comparison between the $\mathrm{H}$ coverage, $\theta_{\mathrm{H}}$, and the Delta XANES data in vacuum can be obtained (for further details, see Fig. 4 in supplementary material). Fig. 11 also shows the experimental $R=I_{1} / I_{2}$ plot as a function of $T$. This line shows the point
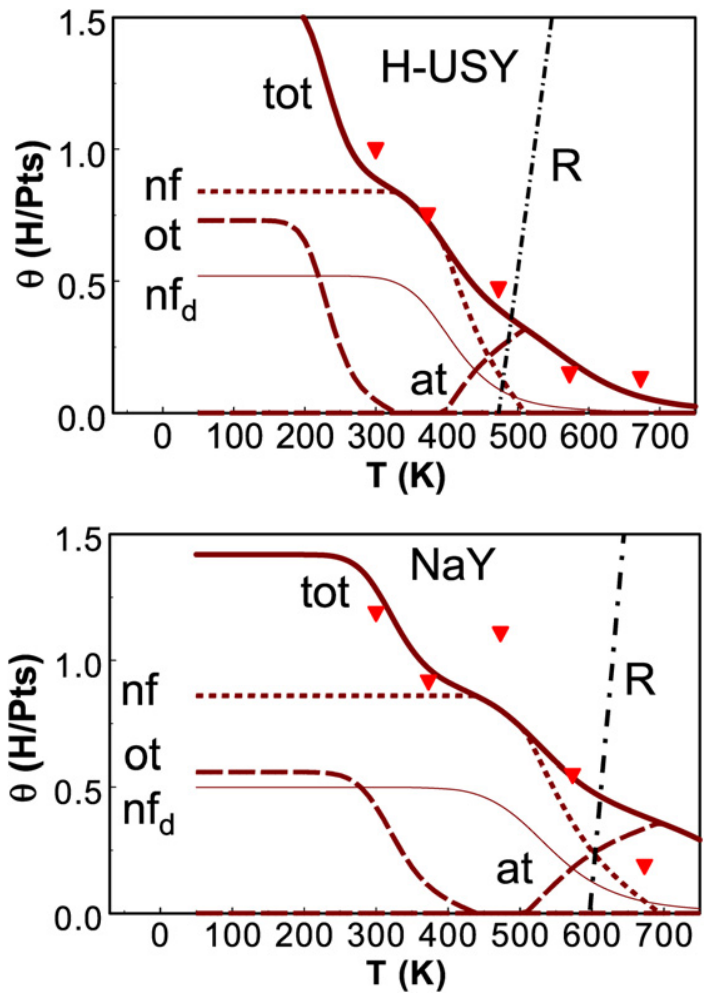

Fig. 11. Calculated coverage as in Fig. 4 but at a $\mathrm{H}_{2}$ pressure of 0.05 atm and using the TPD desorption parameters appropriate for the XANES data taken in flowing $\mathrm{H}_{2}\left(5 \% \mathrm{H}_{2}\right.$ in $\left.\mathrm{He}\right)$. The indicated coverage of each $\mathrm{H}$ site (atop, $n \mathrm{f}$, and ontop) is indicated along with the total coverage. Also indicated is the $n \mathrm{f}_{\mathrm{t}}$ coverage obtained from direct absorption in the $n$-fold sites, and the coverage suggested by the Delta XANES data, obtained by scaling the $\Delta \mu_{L_{2}}$ intensity by the optimal $A$ factors 8.5 for $\mathrm{Pt} / \mathrm{H}-\mathrm{USY}$ and 8.0 for $\mathrm{Pt} / \mathrm{NaY}$.

where the Delta XANES detect the $n$-fold/atop transition, that is, the temperature at which above this line atop $\mathrm{H}$ dominates and below this line $n$-fold $\mathrm{H}$ dominates. Fig. 11 also shows the actual " $n \mathrm{f}$ " coverage, that is, from direct adsorption and from the atop/ $n$-fold arrangement. The $n$-fold coverage arising only from the direct $n$-fold $\mathrm{H}$ adsorption isotherm is designated " $n \mathrm{f}_{\mathrm{d}}$." This $n \mathrm{f}_{\mathrm{d}}$ curve shows the expected behavior and more clearly reveals the effect of the atop/ $n$-fold rearrangement on $\theta_{n \mathrm{f}}$. The point at which the atop/n-fold transition occurs is in excellent agreement with that predicted from the H/M fits. The agreement between the magnitude of the coverages obtained from the H/M fits and the Delta XANES is remarkable, although this latter agreement was built in part by determining the optimal scale factor, $A$.

Nonetheless, the agreement between the Delta XANES and the model coverages over the entire range of the atop $/ n$-fold rearrangement is surprising. It suggest that the scale factor, $A$, must be the same for both the atop and $n$-fold $\mathrm{H}$ even though the $\mathrm{Pt}-\mathrm{H}$ coordination is $n=2$ or 3 for the $n$-fold $\mathrm{H}$, and only 1 for the atop H. As quantified in Fig. 9a for PT/H-USY in $\mathrm{H}_{2}$, $I_{2}\left(L_{2}\right)$ is 0.11 at room temperature $(300 \mathrm{~K})$ for the $n$-fold and only 0.02 at $573 \mathrm{~K}$ for the atop. However, Fig. 11 reveals that $\theta_{\mathrm{H}}$ (mostly $n$-fold) is 0.9 at $300 \mathrm{~K}$ and only about 0.2 (mostly atop) at $573 \mathrm{~K}$. With $\theta_{\mathrm{H}}=A I_{2}, A=\theta_{\mathrm{H}} / I_{2}$, and $A$ comes out to $0.9 / 0.11 \approx 8$ for the $n$-fold and $0.2 / 0.02 \approx 10$ for the atop, 
so that the optimal $A$ comes out to about 8.5. Therefore, the $A$ factors for the atop and $n$-fold sites are comparable, and reasonable agreement between the Delta XANES and the H/M fits throughout the transition region is allowed with one scale factor.

This raises the question: Why are the scale factors for the $n$-fold and atop $\mathrm{H}$ so similar? The scale factor $A$ is expected to be proportional to $n^{*} f / D$, where $n$ is the $\mathrm{Pt}-\mathrm{H}$ coordination ( $n=2$ or 3 for $n$-fold at full coverage and 1 for atop), $f$ is the backscattering factor, and $D$ is the dispersion. Perhaps $f$ in the $n$-fold site is much smaller than for the atop site, making $n \mathrm{f}$ similar for both sites. It is reasonable to expect the $\mathrm{H} 1 \mathrm{~s}$ orbital to be more spread out to the Pt neighbors in the $n$-fold site, which would decrease $f$. However, such a decrease is not predicted by the FEFF8 calculations in Fig. 2, which show that the $\Delta \mu$ is in fact larger for the $n$-fold $\mathrm{H}$ compared with the atop $\mathrm{H}$. Although FEFF8 nicely gives the correct experimental signature of the hydrogen chemisorption site, it may not accurately reproduce the backscattering intensity of the different $\mathrm{H}$ sites, because the "muffin tin" approximation made in FEFF8 is inadequate for such a small, highly polarizable atom. This point needs much further investigation before any firm conclusions can be drawn.

A different scale factor $(A)$ was allowed for $\mathrm{Pt} / \mathrm{NaY}$ versus PT/H-USY ( 8.0 vs 8.5 , respectively) because the Pt dispersion is involved in this factor, as indicated above. The dispersion is expected to be slightly different for these two samples. Therefore, absolute $\mathrm{H}$ coverages can be obtained from the Delta XANES technique using the simple expression $\theta_{\mathrm{H}}=$ $8.0(0.8 / D) I_{2}\left(L_{2}\right)=(6.4 / D) I_{2}\left(L_{2}\right)$, where $D$ is the dispersion, $\mathrm{Pt}_{\mathrm{s}} / \mathrm{Pt}$.

It should be noted that the use of the $N_{i}$ 's in parentheses in Table 2 (maximum of sites indicated for $\mathrm{H}$ desorption vs those obtained directly from the H-uptake fits) do not significantly affect the comparisons between the H/M model with experimental XANES data, except for the position of the rearrangement. This is because the total strongly bonded (at $+n \mathrm{f}$ ) $\mathrm{H}$ coverage stays the same regardless of which $N_{i}$ set in Table 2 is used.

\subsection{Support dependence of hydrogen coverage on Pt}

Tables 1 and 2 reveals the much larger Pt-H binding energies, $\Delta H_{i}$, for Pt particles dispersed in supports with a high ionicity (basic). These results fully confirm the increase in hydrogen chemisorption found on $\mathrm{Pt}$ with increasing ionicity of the support, as reported earlier by our group [9] and implied by our previous theoretical and kinetic studies $[4,10,23]$. The origin of the higher adsorption energy for $\mathrm{H} / \mathrm{Pt}$ in supports with high ionicity lies in the relatively large contribution of $\mathrm{Pt} 6 \mathrm{~s}$ and $6 \mathrm{p}$ states in the $\mathrm{Pt}-\mathrm{H}$ bonding, as we reported previously [26]. This was also reported by Kua and Goddard [8], who performed generalized valence bond calculations on a series of Pt clusters of variable size and showed that hydrogen binds in part via the so-called "interstitial bonding orbital" (IBO). When bulk Pt is involved, Pt atoms share one IBO in each tetrahedron. In fact, this IBO is the bonding combination of the Pt $6 s$ and $6 \mathrm{p}$ orbitals

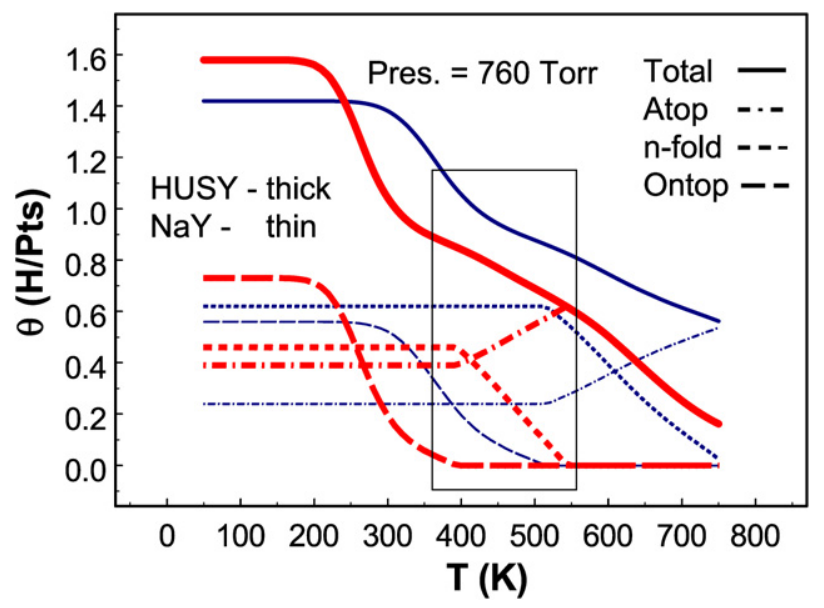

Fig. 12. Same as Fig. 11 but calculated at a $\mathrm{H}_{2}$ pressure of $1 \mathrm{~atm}$. The rectangle indicates typical $\mathrm{H}$ coverages at catalytic reaction temperatures.

in a $\mathrm{Pt}_{4}$ tetrahedron. Although others do not use the IBO terminology, it is generally found that the Pt 6s and 6p states play a significant role in the bonding of $\mathrm{H}$ on Pt [25]. From these results, it can be concluded that the specific symmetry properties of the Pt $6 \mathrm{~s}$ and $6 \mathrm{p}$ orbitals are very beneficial for Pt-H bonding.

We have shown earlier $[10,26]$ that the location of the IBO within the Pt particle shifts from the metal-support interface to the Pt surface with increasing electron richness of the support oxygen atoms (support with high ionicity). When the IBO moves toward the metal-support interface, as is the case for the acidic support, it can no longer participate in the $\mathrm{Pt}-\mathrm{H}$ bond. However, on a basic support, the IBO is located at the surface where it can participate in the $\mathrm{Pt}-\mathrm{H}$ bond. Therefore, the hydrogen coverage is larger for Pt supported on supports with high ionicity.

\subsection{Implications for catalysis}

The Pt Delta XANES data and H/M results presented in this study confirm that the hydrogen coverage, and thus the reactive empty Pt sites available for dissociation of hydrogen and adsorption of reactants present at high-temperature catalytic reaction conditions, strongly depend on the ionicity of the support. Fig. 12 uses the parameters obtained from the H/M fits to calculate the coverage of $\mathrm{H}$ at typical reaction pressures near $1 \mathrm{~atm} \mathrm{H}_{2}$. The rectangle highlights the typical reaction temperatures ( $x$-axis) and the coverage of each individual $\mathrm{H}$ adsorption site ( $y$-axis) [23]. Fig. 12 confirms that indeed the $\mathrm{H}$ coverage for Pt on supports with a different ionicity is quite different at the pressures and temperatures normally used in the catalytic experiments. It also shows that the dominant site for $\mathrm{H}$ chemisorption under these conditions is the atop sites in $\mathrm{Pt} / \mathrm{H}$ USY and the $n$-fold sites in Pt/NaY.

Because Pt particles on acidic supports are the most active in hydrogenation and hydrogenolysis reactions [23], it seems logical to relate the difference in catalytic activity to these differences in $\mathrm{H}_{2}$ chemisorption properties. We have previously reported a full analysis of the kinetic data for hydrogenolysis 
reactions of alkanes catalyzed by Pt particles on supports with different ionicity and acid/base properties [23]. This work has led to a basic understanding of the metal-support interaction on the kinetics of the hydrogenolysis reactions, which is mediated by the $\mathrm{H}$ coverage. The influence of the support on the kinetics of hydrogenation reactions (aromatic saturation) will be explored in subsequent papers. Again, the types of sites available for $\mathrm{H}$ dissociation are different due to a difference in $\mathrm{H}$ coverage on Pt as determined by the ionicity of the support. This is the critical issue in understanding the metal-support interaction for hydrogenation reactions.

\section{Conclusion}

Hydrogen adsorption on Pt/LTL and Pt/Y has been studied as a function of the support ionicity using TPD, Pt $L_{2,3}$ XANES data, and $\mathrm{H}$ chemisorption results. The preferred $\mathrm{H}$ adsorption site can be ascertained from the signature of the Pt Delta XANES spectra. Three different hydrogen adsorption sites have been distinguished: atop, $n$-fold ( $n=2$ or 3 ), and ontop. A Langmuir isotherm has been used for each site, along with a Temkin isotherm for the physisorbed $\mathrm{H}_{2}$ to model the $\mathrm{H} / \mathrm{M}$ results. The model includes a rearrangement of the $\mathrm{H}$ atop sites into $\mathrm{H}$ threefold sites to reduce lateral interactions with increasing coverage. The $\mathrm{Pt}-\mathrm{H}$ bond strength was found to be different for each type of adsorption site, decreasing in the order atop, threefold, and ontop. The parameters obtained from this fit were used to fully model the $\mathrm{H}$ coverage on $\mathrm{Pt}$. It was possible to make a quantitative comparison between the $\mathrm{H} / \mathrm{M}$ data and the results obtained with the Delta XANES technique.

The previously predicted stronger $\mathrm{Pt}-\mathrm{H}$ bond strength $[10$, $26]$ in ionic (basic) supports was confirmed, with the atop $\mathrm{H}$ having a $\mathrm{Pt}-\mathrm{H}$ bond strength over $20 \mathrm{~kJ} /\left(\mathrm{mol} \mathrm{H}_{2}\right)$ stronger for ionic supports. Furthermore, the bond strength at around $80 \mathrm{~kJ} /\left(\mathrm{mol} \mathrm{H}_{2}\right)$ for $\mathrm{H}$ in atop sites in $\mathrm{Pt} / \mathrm{NaY}$ was twice as large as the $40 \mathrm{~kJ} /\left(\mathrm{mol} \mathrm{H}_{2}\right)$ found [3] for $\mathrm{H}$ on $\mathrm{Pt}(111)$ single-crystal surfaces in the threefold sites [ $\mathrm{H}$ did not bond at the atop sites on $\mathrm{Pt}(111)$ ]. This large difference arises from the reduced $\mathrm{Pt}-\mathrm{Pt}$ coordination at corners/edges in the Pt particles.

The atop $/ n$-fold site rearrangement as found in this work fully confirms the DFT calculations reported by us previously [10] and arises due to lateral interactions (both direct and through the $\mathrm{Pt}$ substrate). The atop $/ n$-fold rearrangement appeared to show an interesting hysteresis on $\mathrm{H}$ uptake versus desorption. This hysteresis is believed to result from a requirement for collective rearrangement involving an entire domain or island of $\mathrm{H}$ on the surface.

Application of the three-site adsorption model and use of the determined thermodynamic parameters confirms our Madelung potential model introduced to explain metal-support interaction. A different support ionicity leads to a change in the hydrogen chemisorption properties of supported Pt particles. A different support ionicity produces dramatically different $\mathrm{H}$ coverages and different dominant adsorption sites on $\mathrm{Pt}$ at catalytic reaction temperatures and pressures.

\section{Acknowledgments}

The authors thank the scientific staff in HASYLAB Beamline $\mathrm{X} 1.1$ for their continuing interest and stimulating support. This work was funded by the Materials Engineering Division of Toyota Motor Europe. Fruitful discussions with Yasuo Ikeda and Muriel Lepage of this division and with researchers of Toyota Central R\&D Labs Japan are acknowledged.

\section{Supplementary material}

The online version of this article contains additional supplementary material.

Please visit DOI: 10.1016/j.jcat.2006.10.028.

\section{References}

[1] B.C. Gates, Chem. Rev. 95 (1995) 511.

[2] D.E. Ramaker, D.C. Koningsberger, Phys. Rev. Lett. 89 (2002) 701.

[3] M. Teliska, W.E. O'Grady, D.E. Ramaker, J. Phys. Chem. 108 (2004) 2333.

[4] M.K. Oudenhuijzen, J.A. van Bokhoven, J.T. Miller, D.E. Ramaker, D.C. Koningsberger, J. Am. Chem. Soc. 127 (2005) 1530.

[5] A.L. Ankudinov, B. Ravel, J.J. Rehr, S.D. Conradson, Phys. Rev. B 58 (1998) 7565.

[6] Amsterdam Density Functional Package ADF 2000.02, Department of Theoretical Chemistry, Vrije Universiteit, Amsterdam, http://www.scm. com.

[7] A. Zolfaghari, M. Chayer, G. Jerkiewicz, J. Electrochem. Soc. 144 (1997) 3034.

[8] J. Kua, W.A. Goddard, J. Phys Chem. B 102 (1998) 9481.

[9] Y. Ji, A.M.J. van der Eerden, V. Koot, P.J. Kooyman, D.M. Weckhuysen, D.C. Koningsberger, J. Catal. 234 (2005) 376.

[10] M.K. Oudenhuijzen, J.A. van Bokhoven, D.E. Ramaker, D.C. Koningsberger, J. Phys. Chem. B 108 (2004) 20247.

[11] M. Vaarkamp, F.S. Modica, J.T. Miller, D.C. Koningsberger, J. Catal. 144 (1993) 611.

[12] J.T. Miller, B.L. Meyers, F.S. Modica, G.S. Lane, M. Vaarkamp, D.C. Koningsberger, J. Catal. 143 (1993) 395.

[13] B.L. Mojet, J.T. Miller, D.E. Ramaker, D.C. Koningsberger, J. Catal. 186 (1999) 373.

[14] M. Vaarkamp, B.L. Mojet, F.S. Modica, J.T. Miller, D.C. Koningsberger, J. Phys. Chem. 99 (1995) 16067.

[15] C.M.A. Brett, A.M.O. Brett, Electrochemistry, Principles, Methods, and Applications, Oxford Science Publ., Oxford, 2000, p. 55.

[16] A.M. Argo, J.F. Odzak, F.S. Lai, B.C. Gates, Nature 415 (2002) 623.

[17] S.G. Podzolkin, R.M. Watwe, Q. Yan, J.J. de Pablo, J.A. Dumesic, J. Phys. Chem. B 105 (2001) 8550.

[18] P.W. Atkins, Physical Chemistry, third ed., W.H. Freeman, New York, 1986, p. 817.

[19] F.W. Lytle, R.B. Greegor, E.C. Marques, V.A. Biebesheimer, D.R. Sandstrom, A. Horsley, G.H. Via, J.H. Sinfelt, ACS Symp. Ser. 288 (1985) 280.

[20] T. Kubota, K. Asakura, N. Ichikuni, Y. Iwasawa, Chem. Phys. Lett. 256 (1996) 445.

[21] S.N. Reifsnyder, M.M. Otten, D.E. Sayers, H.H. Lamb, J. Phys. Chem. B 101 (1997) 4972.

[22] D.E. Ramaker, B.L. Mojet, M.T. Garriga Oostenbrink, J.T. Miller, D.C. Koningsberger, Phys. Chem. Chem. Phys. 1 (1999) 2293.

[23] D.C. Koningsberger, M.K. Oudenhuijzen, J. de Graaf, J.A. van Bokhoven, D.E. Ramaker, J. Catal. 216 (2003) 178.

[24] P.J. Feibelman, D.R. Hamann, Surf. Sci. 182 (1987) 411.

[25] G. Papoian, J.K. Nørskov, R. Hoffmann, J. Am. Chem. Soc. 122 (2000) 4129.

[26] D.E. Ramaker, J. de Graaf, J.A.R. van Veen, D.C. Koningsberger, J. Catal. 203 (2001) 7. 